\title{
Numerical Study on the Seismic Response of Structure with Consideration of the Behavior of Base Mat Uplift
}

\author{
Guo-Bo Wang, ${ }^{1}$ Xin Zhou, ${ }^{1}$ Xian-Feng $M a,{ }^{2,3}$ and Jun $\mathrm{Wu}^{4}$ \\ ${ }^{1}$ Hubei Key Laboratory of Roadway Bridge \& Structure Engineer, Wuhan University of Technology, Wuhan 430070, China \\ ${ }^{2}$ The Key Laboratory of Geotechnical and Underground Engineering of the Ministry of Education, \\ Tongji University, Shanghai 200092, China \\ ${ }^{3}$ Department of Geotechnical Engineering, Tongji University, Shanghai 200092, China \\ ${ }^{4}$ School of Urban Railway Transportation, Shanghai University of Engineering Science, Shanghai 201620, China \\ Correspondence should be addressed to Xian-Feng Ma; xf.ma@tongji.edu.cn
}

Received 12 June 2017; Accepted 31 July 2017; Published 3 October 2017

Academic Editor: Xing Ma

Copyright (C) 2017 Guo-Bo Wang et al. This is an open access article distributed under the Creative Commons Attribution License, which permits unrestricted use, distribution, and reproduction in any medium, provided the original work is properly cited.

The foundation might be separated from the supporting soil if the earthquake is big enough, which is known as base mat uplift. This paper proposed a simplified calculation model in which spring element is adopted to simulate the interaction between soil and structure. The load-deformation curve ( $F-D$ curve) of the spring element can be designated to represent the base mat uplift, in which the pressure can be applied while tensile forces are not allowed. Key factors, such as seismic wave types, seismic wave excitation directions, seismic wave amplitudes, soil shear velocities, structure stiffness, and the ratio of structure height to width $(H / B)$, were considered in the analysis. It is shown that (1) seismic wave type has significant influence on structure response due to different frequency components it contained; (2) the vertical input of seismic wave greatly affected structure response in vertical direction, while it has little impacts in horizontal direction; (3) base mat uplift is easier to take place in soil with higher shear velocity; (4) structure $H / B$ value has complicated influence on base mat uplift. The outcome of this research is assumed to provide some references for the seismic design of the structure due to base mat uplift.

\section{Introduction}

There have been two ways to deal with the soil-structure interaction (SSI) effect in seismic design of structures: one is treating the soil as rigid medium and neglecting the SSI effect; the other is assuming the foundation to be fully bonded to soil so that the foundation uplift cannot occur. However, the importance of the SSI in the dynamic response of structure has been realized recently by researchers, though foundation uplift has not gotten enough attention yet, partly due to the fact that interfacial behavior between foundation and soil cannot be directly observed after earthquake. However, the phenomenon of foundation uplift can be verified indirectly in some earthquakes such as that of Chile 1960, Alaska 1964, San Fernando 1971, Kocaeli 1999, and Athens 1999 [1], in which snow was observed under the structural base mat.
Housner [2] found that several golf-ball-on-a-tee type of elevated water tanks survived from ground shaking whereas the reinforced concrete structures of elevated water tanks were severely damaged during the Chilean earthquake in 1960. Motivated by this phenomena, Housner further investigated dynamic response of rigid block rocking on rigid horizontal base to establish the relationship between structure and foundation uplift. After that, the impact of foundation uplift on the dynamic response of structures had attracted much interest of earthquake related researchers. Early research works focused on rigid block rocking on rigid base [3] or elastic/Winkler base [4, 5], in which the influence of structure flexibility on dynamic response of structure is neglected. Later, calculation models for flexible blocks/structure rocking on rigid base $[6,7]$ and elastic base $[8,9]$ were proposed (see Figure 1). 


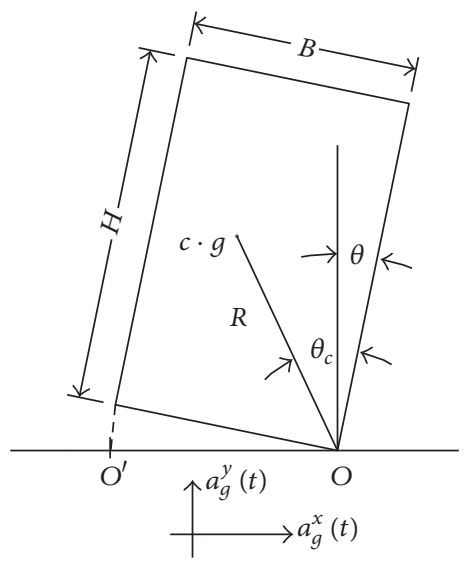

(a)

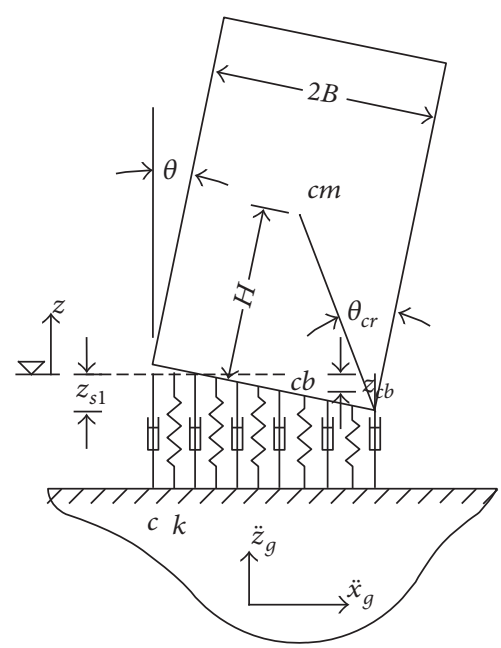

(b)

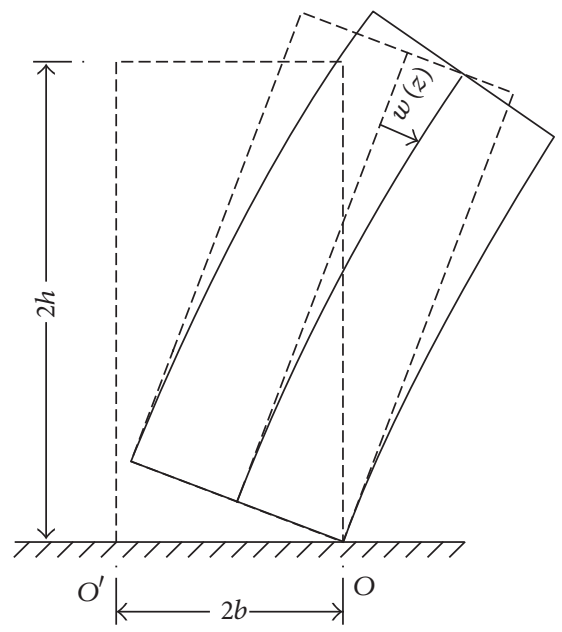

(c)

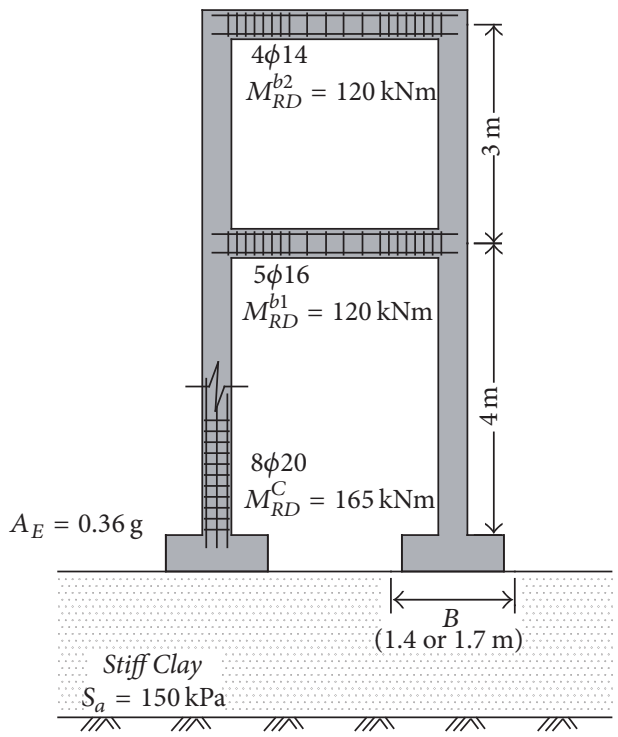

(d)

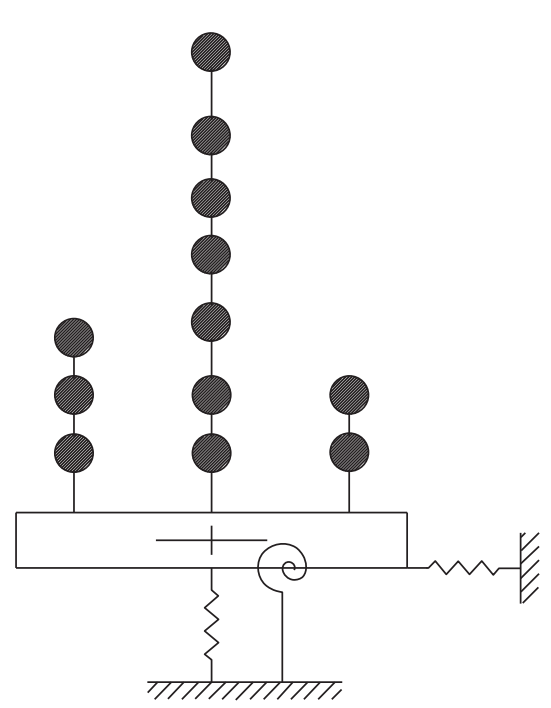

(e)

Figure 1: Four calculation models. (a) Rigid block rocking on rigid base [3]; (b) rigid block rocking on Winkler base [4]; (c) flexible block rocking on rigid base [6]; (d) practical structure rocking on elastic base [8]; (e) SR model [10].

With the construction of nuclear power plant (NPP) structures in Japan and America, much attention had been paid to the impact of base mat uplift on the seismic response of structure. The SR (Away-Rocking) model (as shown in Figure 1(e)) was developed and used widely for the analysis of the dynamic response of NPP due to its complicate property. Kennedy et al. [13] established a simplified dynamic mathematical model for a typical High Temperature Gascooled Reactor (HTGR) plant. The results showed that linear analysis may be used to determine all structural response for rock sites even when there is substantial base slab uplift. However, for soil sites, nonlinear analyses on structure should be conducted if base mat uplift occurs. Taking a reactor building of Pressurized Water Reactor (PWR) plant as an example, Sotomura and Kase [10] investigated the impact of the vertical and horizontal ground motion on the seismic response of structure due to base mat uplift. With the development of computing resource, numerical simulation methods have been employed to conduct the three-dimensional nonlinear calculation. Naohiro et al. [14] established a three-dimensional nonlinear FEM model to calculate the seismic response of a nuclear power plant with consideration of base mat uplift during earthquake. The ultimate displacement of structure and its fragility were then evaluated. Bolisetti and Whittaker [15] analyzed the influence of adjacent structures on foundation uplift in NPP structures by finite element method, in which the contact element or joint element was used to represent the behavior of the base mat uplift. Yabushita et al. [16] and Naohiro et al. [17] studied the nonlinear behavior of base mat uplift by arranging joint elements between the reactor building base mat and the underneath soil in 3D FE model. However, such 


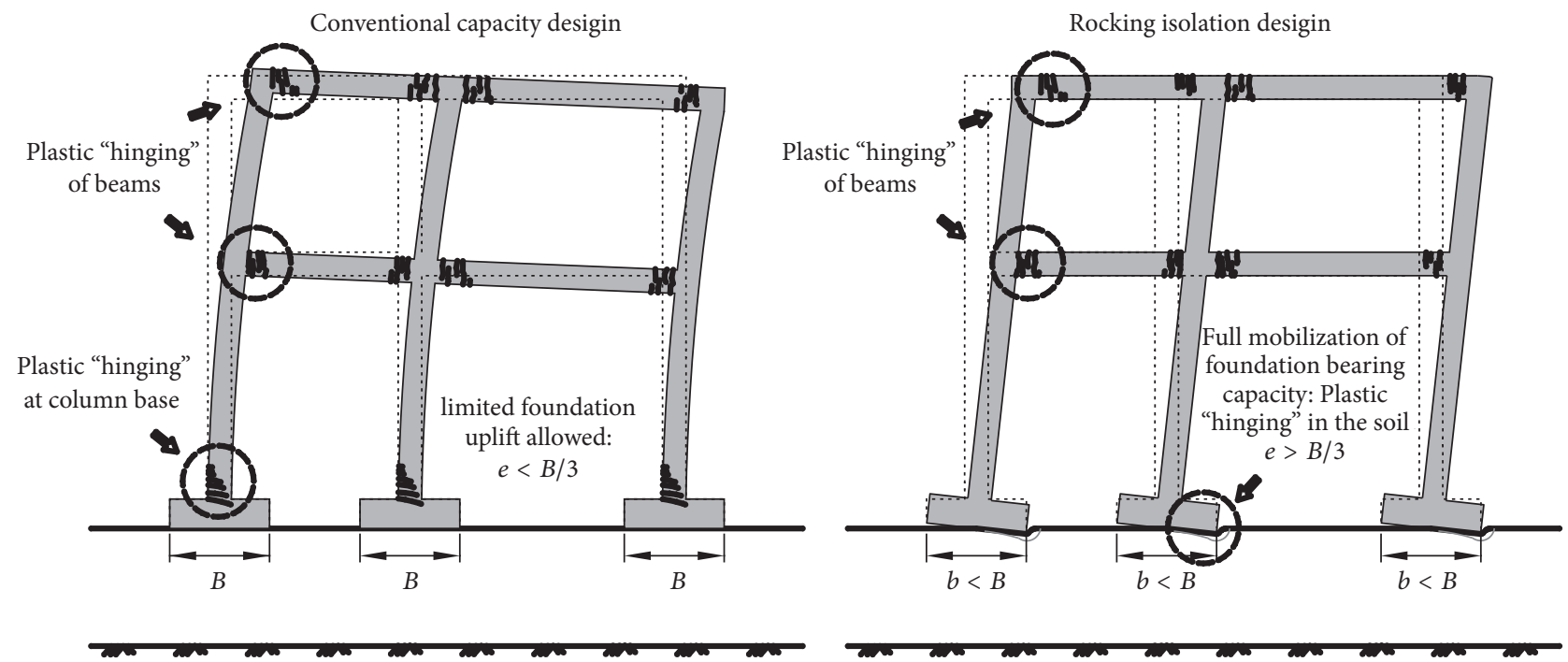

FIGURE 2: The principle of the new idea "rocking isolation" [11, 12].

FE method suffered two key problems, that is, the difficulty in determination of constitutive models for contact/joint element and convergent issue in $\mathrm{FE}$ analysis.

Recently, Gazetas et al. [11, 12] proposed a concept of rocking isolation, in which the influence of foundation uplift on seismic response of structure can be investigated. Preliminary results showed that foundation uplift was beneficial to dynamic behavior of structure during earthquake. Compared to the current prevailing "capacity design" philosophy, Gazetas proposed the idea of rocking isolation, taking advantage of the nonlinear characteristics of surrounding soil in the phenomenon of SSI, and then they intentionally induced the plastic hinging in the element of foundation and soil (as shown in Figure 2) to mobilize the strength of the surrounding soil. Anastasopoulos et al. $[18,19]$ analyzed the impact of rocking isolation on an asymmetric frame structure and a retrofitted three-story building, and it is observed that the rocking isolation in structure can offer increased safety margins. Gazetas et al. [11, 12] suggested that seismic safety factors can be reduced to 1 by adopting the idea of rocking isolation.

From the initial study on the rigid block rocking at the rigid base to the up-to-data conception of rocking isolation, one crucial problem has not been solved perfectly, that is, how to establish a suitable calculation model to compute seismic response of block/structure due to base mat/foundation uplift. It is obvious that the nonlinear property of surrounding soil cannot be considered in the traditional analysis model as shown in Figures 1(a), 1(b), and 1(c), and the threedimensional effect cannot be included in the SR model as shown in Figure 1(e). The real three-dimension FE model, as given in Figures 1(d) and 2, might overcome the above shortcomings; however, there are highly demanding computational time and resource, and hence it is unsuitable for practical designers. Most importantly, the rocking system is a time varying system, which means the stiffness, frequency, period, and damping are changing with the amount and area of foundation uplift. In order to establish a robust calculation method with consideration of the foundation uplift, the "stress redistribution phenomenon" must be considered. In this paper, a spring element method is proposed to avoid the convergence issue in the contact/joint element method and then the seismic response of structure due to the foundation uplift can be analyzed systematically. Although this method cannot consider nonlinear character of surrounding soil, the research work here can give some insight to the seismic response of structure due to foundation uplift and then provides the theoretical foundation for further work with consideration of the nonlinear property of soil. At same time, some key factors impact on the seismic structural response and foundation uplift ratio are also discussed.

\section{New Computational Method Using Spring Element}

2.1. Traditional Method. The development of the calculation method for seismic response of structure considering base mat uplift has experienced three stages. The first stage was focusing on block rocking on soil surface. Chopra and Yim [20] established analytic formulae for a rigid and flexible body rocking on rigid foundation, from which the classic Winkler foundation model and simplified two-element foundation model were proposed. The SR model was then proposed in the second stage to analyze the linear seismic responses of structure [21]. It should be noticed that only $2 \mathrm{D}$ analyses were conducted in first two stages. The 3D FE method was employed in the third stage, in which the contact element or joint element was used to consider the soil-structure interaction and the behavior of base mat uplift $[17,22]$. It should be mentioned that the 3D FE model can be used to conduct nonlinear analysis since the nonlinear property of material and geometry can be incorporated in a 3D FE model.

2.2. The Basic Principle of the New Method. The computation efficiency for contact element and joint element is usually 


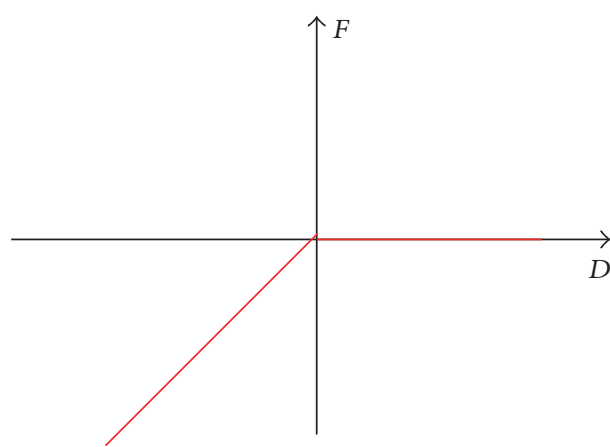

FIgURE 3: $F$ - $D$ curve for COMBIN39 element.

very low due to the difficulty of convergence in nonlinear analysis. In order to overcome this deficiency, a new computational method is suggested in this paper, in which the contact or joint element is replaced by spring element. The spring elements, COMBIN39 in the FE software ANSYS, can provide pressure by setting its load-deformation curve ( $F-D$ curve) as shown Figure 3, and the tensile forces are not allowed. It is obvious that the base mat uplift will occur if the vertical displacement of node at base mat is larger than zero. The values of spring stiffness and damping ratio or damping coefficient can be determined by classic empirical formulae for soil impedance, which will be given in the following section.

2.3. Implementation of the New Method. The spring element in FE software ANSYS has the feature of "no length," which means that the two nodes at each end of the spring element will locate at the same position. It should be noticed that the nodes in Figure 4 are layered deliberately for the sake of explanation of the occurrence of base mat uplift. The process of simulation can be classified into four phases.

(a) Before the Phase of Computation. The point $O$ is set as the original coordinate to establish the FE model of structure, in which the positive direction is assumed to be upwards (Figure 4(a)).

(b) Phase of Static Analysis. The spring element will be compressed under the self-weight of the structure and reach the static equilibrium at certain position (see the dotted line in Figure 4(a)).

(c) Phase of Seismic Excitation. The structure will rock left and right under the seismic excitation. Critical state is defined as the situation when the vertical displacement of the corner node at base mat is equal to zero (see Figure 4(b) and node 1 in Figure 6).

(d) Phase of Base Mat Uplift. The vertical displacement of base mat will increase with the increase of the amplitude of input seismic wave, and, accordingly, the base mat uplift will occur due to no tensile force being allowed in the spring element (see Figure 4(c)).

The base mat will touch the soil again if the peak acceleration of the seismic wave passes through. It should be noted that the shock effect between soil and base mat will not be considered here for the sake of simplicity.

\section{Calculation Model}

3.1. Simplified Calculation Model. In current study, a fourstory frame structure (as shown in Figure 5) is taken as a typical structure in the analysis. The base mat is $12 \mathrm{~m}$ square and the height of each story is $3 \mathrm{~m}$. The section of each column is $0.6 \mathrm{~m}$ in both width and length. The mass density of the concrete is set to $2600 \mathrm{Kg} / \mathrm{m}^{3}$, modulus of elasticity is $36 \mathrm{GPa}$, and the Poisson ratio is 0.2 . The total weight of the structure is calculated to be $7.38 \times 10^{6} \mathrm{~N}$.

In the FE model, the beam is simulated with BEAM188 element, and the wall and slab are represented by SHELL181 element. The total number of element and node are 2274 and 1326 , respectively. The axes of $X$ and $Z$ are set in horizontal directions and $Y$ is in vertical direction.

3.2. Soil Model. Soil is modelled by spring-damping element (COMBIN39 element), which has six degrees of freedom in each node: two horizontal directions, one vertical direction, two rocking directions, and one torsion direction. The shear wave velocity, mass density, and Poisson ratio of the soil are $1100 \mathrm{~m} / \mathrm{s}, 2350 \mathrm{Kg} / \mathrm{m}^{3}$ and 0.4 , respectively.

3.3. Soil Impedance Computation. In current research, the rigid foundation is considered to be rested on the surface of a half space. The embedded depth of foundation $\mathrm{H}$ is neglected for a conservative treatment.

The formulae suggested by Veletsos and Verbic [23] are employed in this research as the expressions are frequencydependent, which is much more rational. The formulae are given in Tables 1 and 2, and the calculation results are listed in Table 4.

The recommended formulae in ASCE code (Table 3) are also used to verify Table 2's calculation results.

It can be seen from Table 4 that the calculated stiffness and damping by two methods are almost the same.

3.4. Damping. The damping in a soil-structure interaction system mainly consists of two parts: soil damping and structure damping. Soil damping can be calculated by soil impedance functions, that is, the formulae listed in Table 1 or Table 3. According to the results from Rotaru et al. [25] and German standards [26], it is suggested that if the calculated damping values of soil are too big, the damping value in horizontal and vertical direction for soil can be cut off by $15 \%$ and 30\%, respectively. Structure damping is considered to be Rayleigh damping, which can be expressed by the following formulae:

$$
\begin{aligned}
& C=\alpha[M]+\beta[K], \\
& \alpha=\frac{2 \omega_{1} \omega_{2} \xi}{\omega_{1}+\omega_{2}}, \\
& \beta=\frac{2 \xi}{\omega_{1}+\omega_{2}},
\end{aligned}
$$




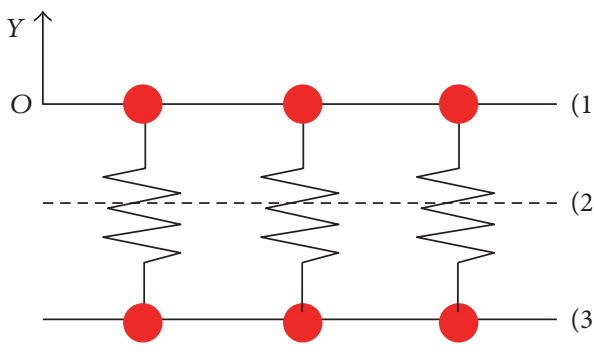

(a) Before analysis and static equilibrium phase

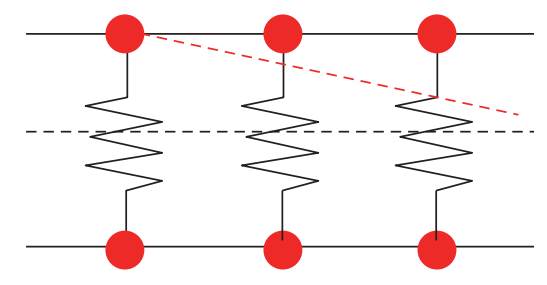

(b) Critical state

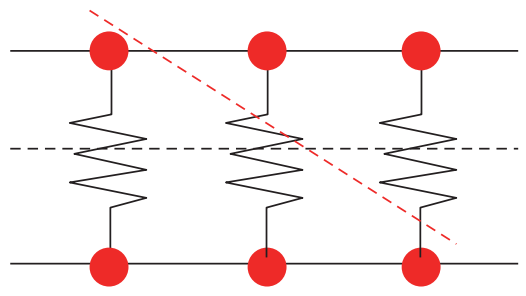

(c) Base mat uplift phase

Figure 4: Schematic diagram of the working state of spring element. (1) base mat plane, (2) static equilibrium plane, and (3) copied plane (for the establishment of spring element).

TABLE 1: Soil impedance functions for circular foundation on a half-space [23].

\begin{tabular}{lccc}
\hline Mode & $K_{\text {st }}$ & $k$ & $c$ \\
\hline Horizontal & $\frac{8 G R}{2-v}$ & $k_{x}=k_{y}=1$ & $c_{x}=c_{y}=\alpha_{1}$ \\
Vertical & $\frac{4 G R}{1-v}$ & $k_{z}=1-\gamma_{1} \frac{\left(\gamma_{2} a_{0}\right)^{2}}{1+\left(\gamma_{2} a_{0}\right)^{2}}-\gamma_{3} a_{0}^{2}$ & $c_{z}=\gamma_{4}+\gamma_{1} \gamma_{2} \frac{\left(\gamma_{2} a_{0}\right)^{2}}{1+\left(\gamma_{2} a_{0}\right)^{2}}$ \\
Rocking & $\frac{8 G R^{3}}{3(1-v)}$ & $k_{\psi}=1-\beta_{1} \frac{\left(\beta_{2} a_{0}\right)^{2}}{1+\left(\beta_{2} a_{0}\right)^{2}}-\beta_{3} a_{0}^{2}$ & $c_{\psi}=\beta_{1} \beta_{2} \frac{\left(\beta_{2} a_{0}\right)^{2}}{1+\left(\beta_{2} a_{0}\right)^{2}}$ \\
Torsion & $\frac{16 G R^{3}}{3}$ & $k_{\theta}=1-0.425 \frac{\left(0.687 a_{0}\right)^{2}}{1+\left(0.687 a_{0}\right)^{2}}$ & $c_{\theta}=0.425 \times 0.687 \frac{\left(0.687 a_{0}\right)^{2}}{1+\left(0.687 a_{0}\right)^{2}}$ \\
\hline
\end{tabular}

$\alpha_{1}, \beta_{i}$, and $\gamma_{i}$ are numerical coefficients which depend on Poisson's ratio $v$ as shown in Table 2.

TABLE 2: Values for fitting parameters of $\alpha_{1}, \beta_{i}$, and $\gamma_{i}$ [23].

\begin{tabular}{lcccc}
\hline Quantity & $v=0$ & $v=1 / 3$ & $v=0.45$ & $v=0.5$ \\
\hline$\alpha_{1}$ & 0.775 & 0.65 & 0.6 & 0.6 \\
\hline$\beta_{1}$ & 0.8 & 0.8 & 0.8 & 0.8 \\
$\beta_{2}$ & 0.525 & 0.5 & 0.45 & 0.4 \\
$\beta_{3}$ & 0 & 0 & 0.023 & 0.027 \\
\hline$\gamma_{1}$ & 0.25 & 0.35 & - & 0 \\
$\gamma_{2}$ & 1.0 & 0.8 & - & 0 \\
$\gamma_{3}$ & 0 & 0 & - & 0.17 \\
$\gamma_{4}$ & 0.85 & 0.75 & - & 0.85 \\
\hline
\end{tabular}

where $\xi$ is the damping ratio and $\omega_{1}$ and $\omega_{2}$ are system natural frequencies. Generally, the damping is set to be 0.05 , and structure first-order natural frequency and the tenth-order natural frequency are selected for $\omega_{1}$ and $\omega_{2}$ in current study.

3.5. Computation Time Step. As high frequency contents will be generated in the occurrence of base mat uplift, the time step is selected to be $0.002 \mathrm{~s}$, which is small enough to consider the influence of high frequency contents.

\section{Influencing Factors}

There are many factors that impact the seismic response of structure, like velocity of shear wave, type and amplitude of seismic wave, structure stiffness, the ratio of structure height to width, and so on. The following factors are considered in this papers.

(1) Amplitude of Seismic Wave. According to Chinese code [27], the amplitude of seismic wave in terms of ultimate safety in ground motion is $0.15 \mathrm{~g}$ and should not be bigger than $0.5 \mathrm{~g}$ for seismic design of nuclear power plants. Therefore, three amplitudes are considered: $0.15 \mathrm{~g}, 0.5 \mathrm{~g}$, and $1 \mathrm{~g}$ ( $1 \mathrm{~g}$ is for the sake of comparison).

(2) Direction of Seismic Waves. According to Chinese code, the direction of input seismic wave in model should be applied at two horizontal and one vertical direction simultaneously. Due to the symmetry of the structure, the seismic waves are input only in one horizontal $(X)$ and one vertical $(Y)$ directions in current study. The amplitude of seismic wave in vertical direction is set to be two-thirds of that in horizontal direction. Furthermore, in order to analyze the influence of vertical seismic wave on the dynamic response of structure, the case having only horizontal seismic wave input is also considered.

(3) Type of Seismic Wave. EL-Centro wave is selected as first input wave, and Songpan wave is used as the second one, which is recorded in Wenchuan earthquake in 2008 in China, and Taft wave is then used for comparison purpose. The time history and Fourier spectrum curves for above three types of seismic wave are illustrated in Figure 7, and their amplitudes are scaled to be $0.15 \mathrm{~g}, 0.5 \mathrm{~g}$, and $1 \mathrm{~g}$, respectively. 
TABLE 3: Soil impedance functions recommended in ASCE code [24].

\begin{tabular}{lcr}
\hline Motion & Equivalent spring constant & Damping coefficient \\
\hline Horizontal & $K_{x}=32(1-v) \frac{G R}{7-8 v}$ & $C_{x}=0.576 K_{x} R \sqrt{\frac{\rho}{G}}$ \\
Rocking & $K_{\psi}=\frac{8 G R^{3}}{3(1-v)}$ & $C_{\psi}=\frac{0.3}{1+B_{\psi}} K_{\psi} R \sqrt{\frac{\rho}{G}}$ \\
Vertical & $K_{z}=\frac{3 G R}{1-v}$ & $C_{z}=0.85 K_{z} R \sqrt{\frac{\rho}{G}}$ \\
Torsion & $K_{t}=\frac{16 G R^{3}}{3}$ & $C_{t}=\frac{\sqrt{K_{t} I_{t}}}{1+2 I_{t} / \rho R^{5}}$ \\
\hline
\end{tabular}

Note. $v, G$, and $\rho$ are soil Poisson ratio, shear modulus, and mass density and $R$ is the equivalent radius of structure base mat. $B_{\psi}=\left[3(1-v) I_{0}\right] /\left(8 \rho R^{5}\right)$, in which $I_{0}$ is the mass moment of inertia about the rocking axis at structure base mat and $I_{t}$ is structure polar mass moment of inertia.

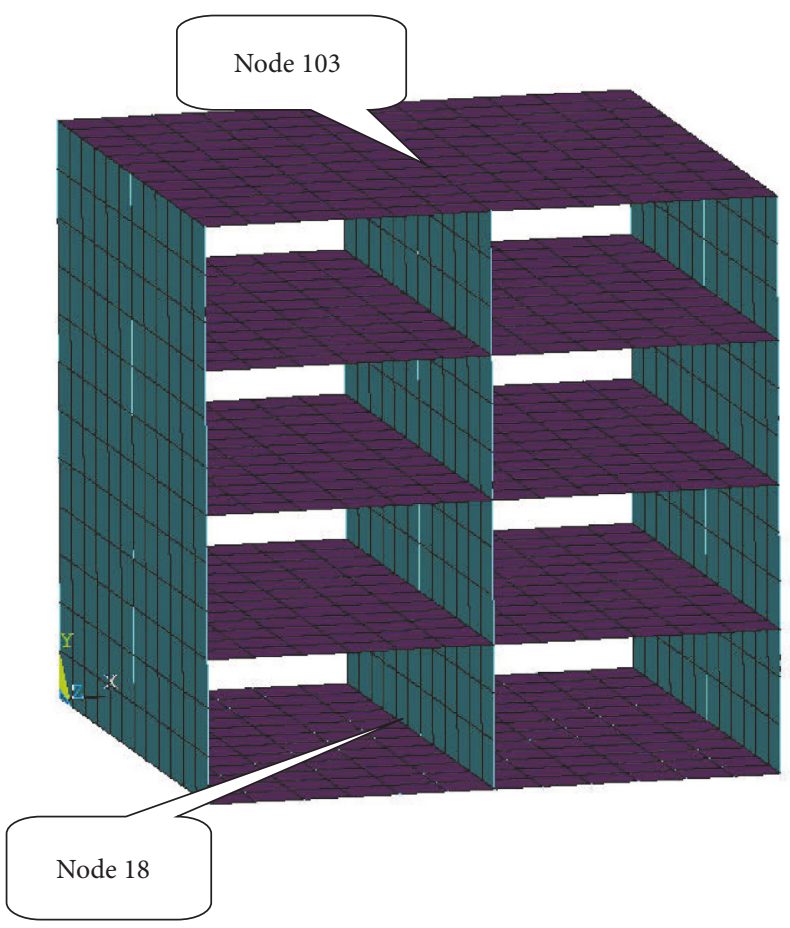

FIgURE 5: Computation model.

TABLE 4: Calculation results comparison between two methods.

\begin{tabular}{lcccc}
\hline \multirow{2}{*}{ Motion } & \multicolumn{2}{c}{$K$} & \multicolumn{2}{c}{$c$} \\
& Veletsos & ASCE & Veletsos & ASCE \\
\hline Horizontal/N/m & $9.01 E 10$ & $9.73 E 10$ & 0.63 & 0.58 \\
Rocking/N*m & $1.96 E 12$ & $1.81 E 12$ & 0.15 & 0.11 \\
Vertical/N/m & $8.97 E 10$ & $9.63 E 10$ & 0.83 & 0.72 \\
Torsion/N*m & $2.33 E 12$ & $2.09 E 12$ & 0.16 & 0.12 \\
\hline
\end{tabular}

(4) Soil Parameters. Based on Chinese code, the soil-structure interaction effect can be neglected if the velocity of shear wave in soil is bigger than $1100 \mathrm{~m} / \mathrm{s}$. In this study, three velocities of shear wave in soil are considered: $2000 \mathrm{~m} / \mathrm{s}, 1100 \mathrm{~m} / \mathrm{s}$, and $400 \mathrm{~m} / \mathrm{s}$.

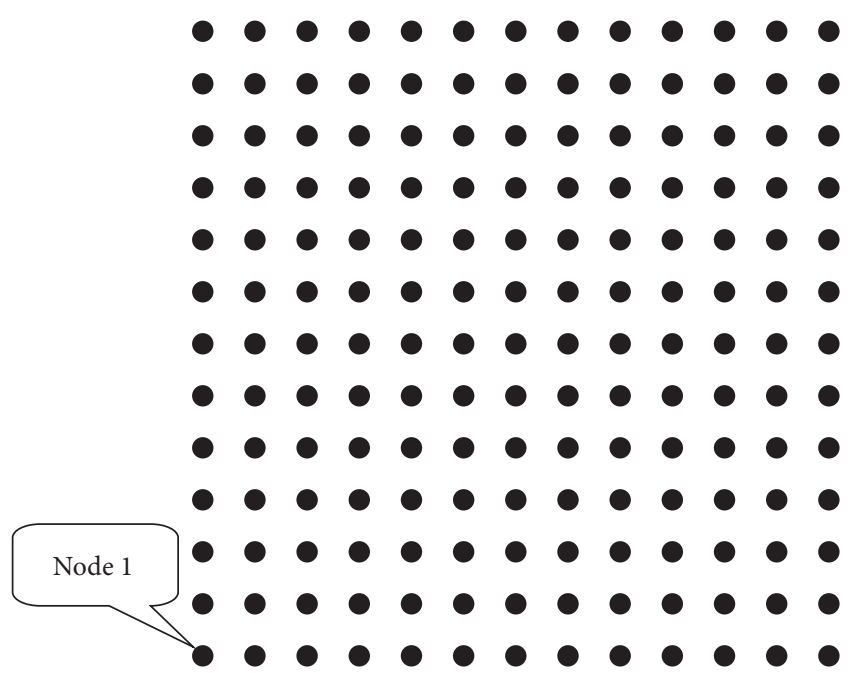

FIgURE 6: Plan view of base mat.

\section{Modal Analysis}

Modal analysis is firstly conducted on structure system. The first five natural frequencies and their corresponding vibration modes are given in Table 5.

\section{Analysis of the Standard Case}

The standard case is defined as that where the structure is excited by the EL wave in horizontal direction with peak acceleration of $0.5 \mathrm{~g}$ and vertical direction with peak acceleration of $0.33 \mathrm{~g}$ simultaneously (labeled as HV case), and the velocity of shear wave is set to be $1100 \mathrm{~m} / \mathrm{s}$.

6.1. Floor Acceleration and Corresponding Fourier Spectrum. The time history of horizontal and vertical acceleration and its corresponding Fourier spectrum curves for the fourth floor (the node 103 in Figure 4) and the first floor (node 18 in Figure 4) are given in Figures 8 and 9, respectively. It is observed that the amplitudes of acceleration are different for different floors, and the amplitude of acceleration increases with the structure height. It is also found that horizontal acceleration 
TABLE 5: The first five natural frequencies and corresponding vibration mode.

\begin{tabular}{lccccc}
\hline Order & 1 & 2 & 3 & 4 & 5 \\
\hline Frequency/Hz & 1.9581 & 7.4998 & 10.961 & 12.309 & 14.572 \\
Vibration Mode & Horizontal & Horizontal & Structure torsion about vertical axis & Floor torsion about vertical axis & Vertical \\
\hline
\end{tabular}
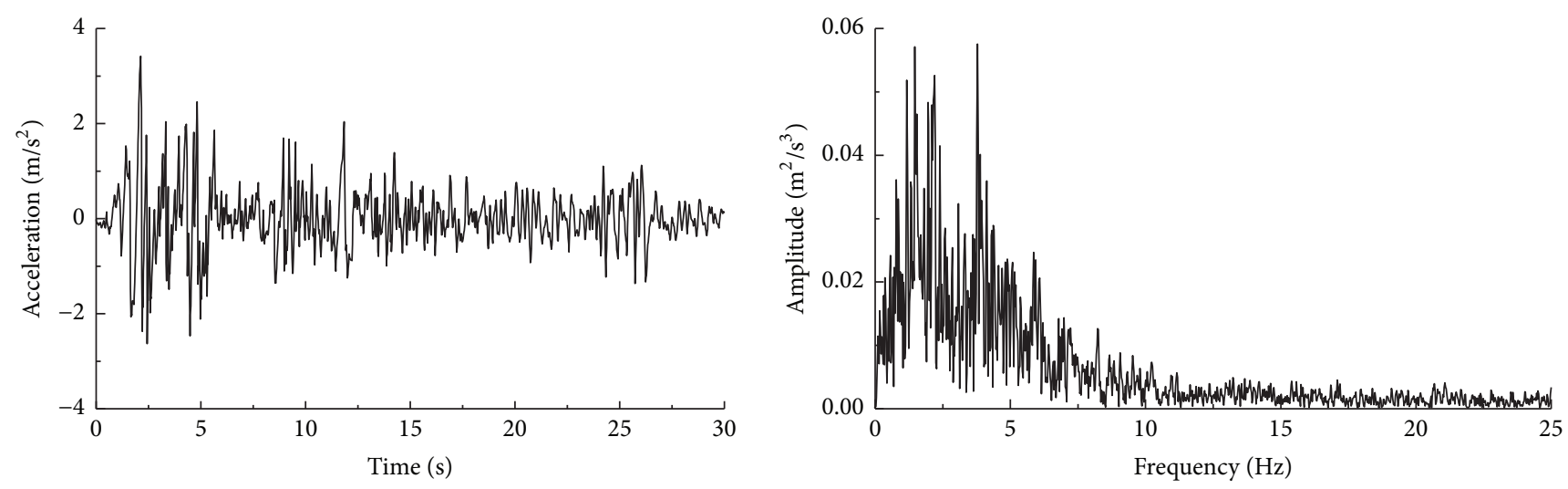

(a) El-Centro wave
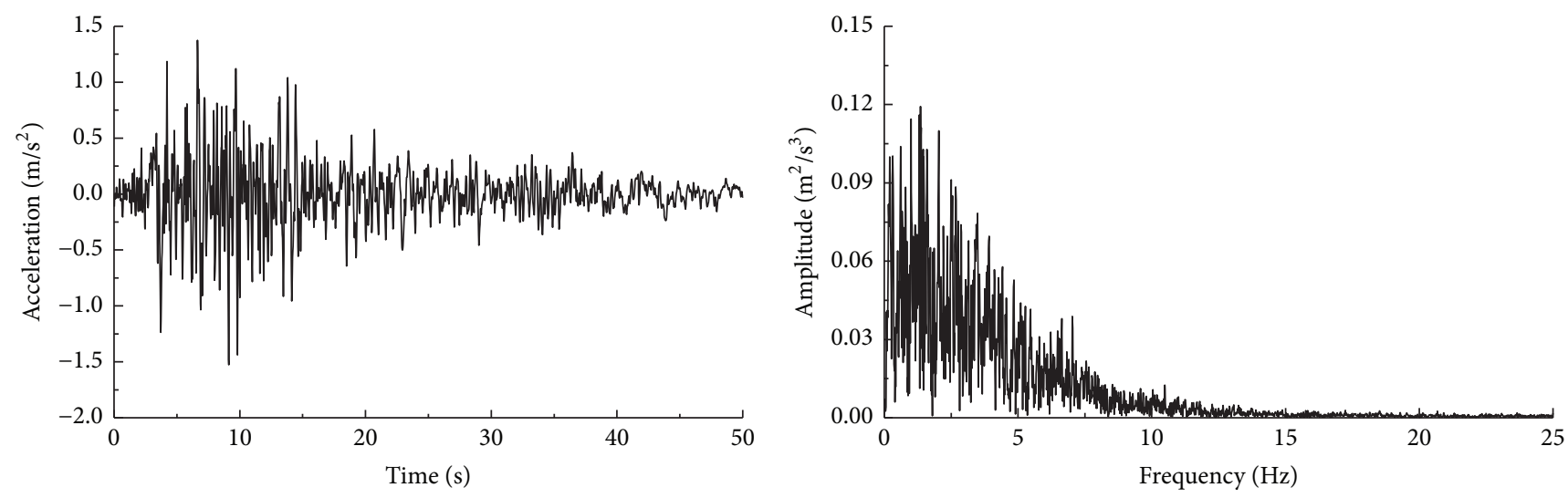

(b) Taft wave
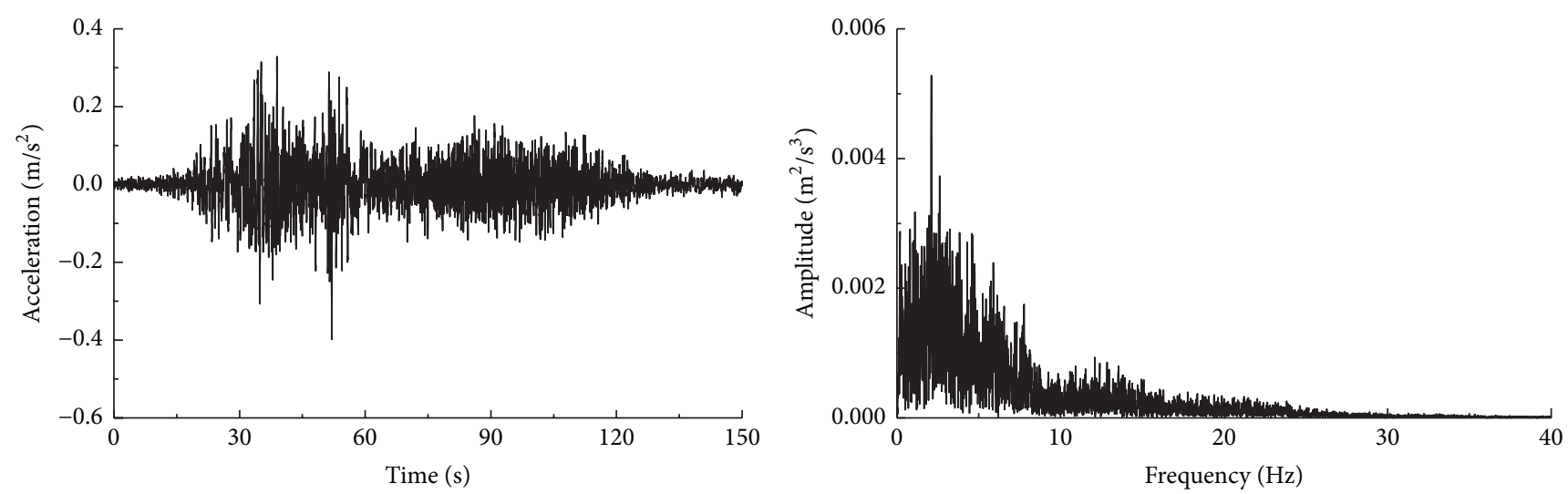

(c) Songpan wave

FIGURE 7: Time history and Fourier spectrum curves of input waves. 

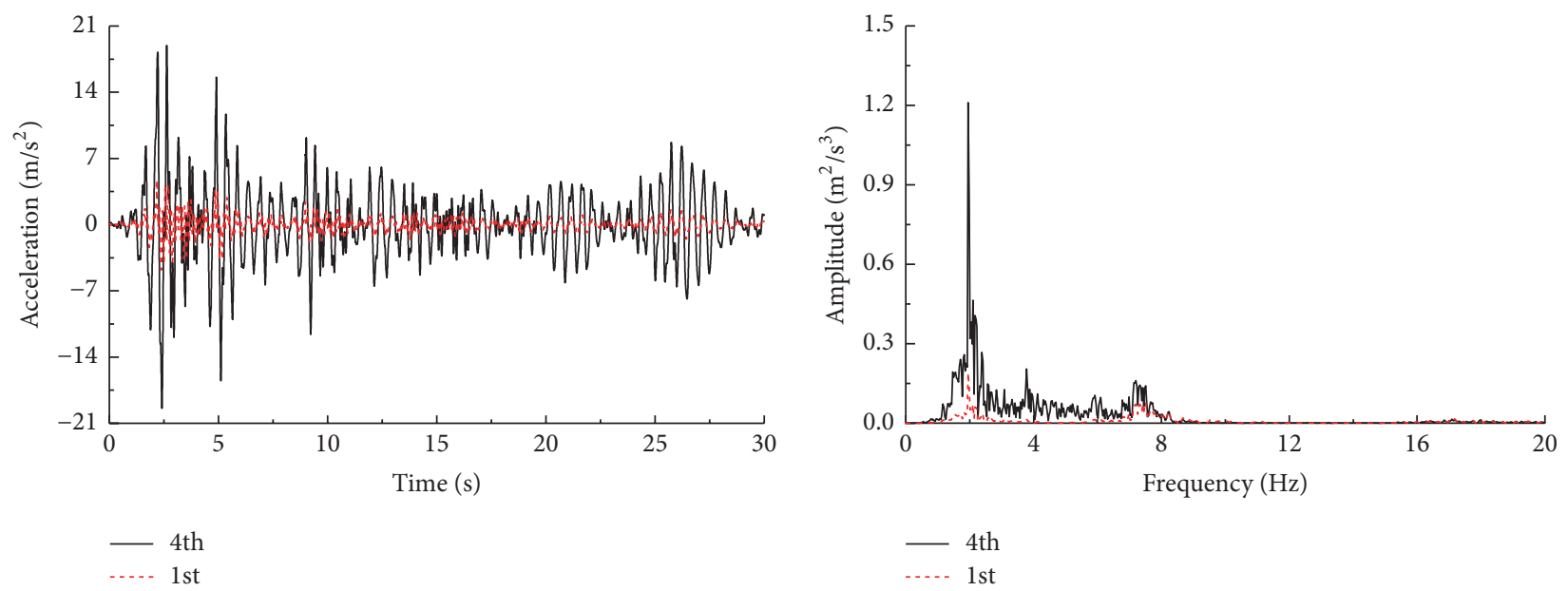

FiguRE 8: Horizontal acceleration time history and corresponding Fourier spectrum curves at node 103 on the 4 th floor and node 18 on the 1st floor under standard case (HV).
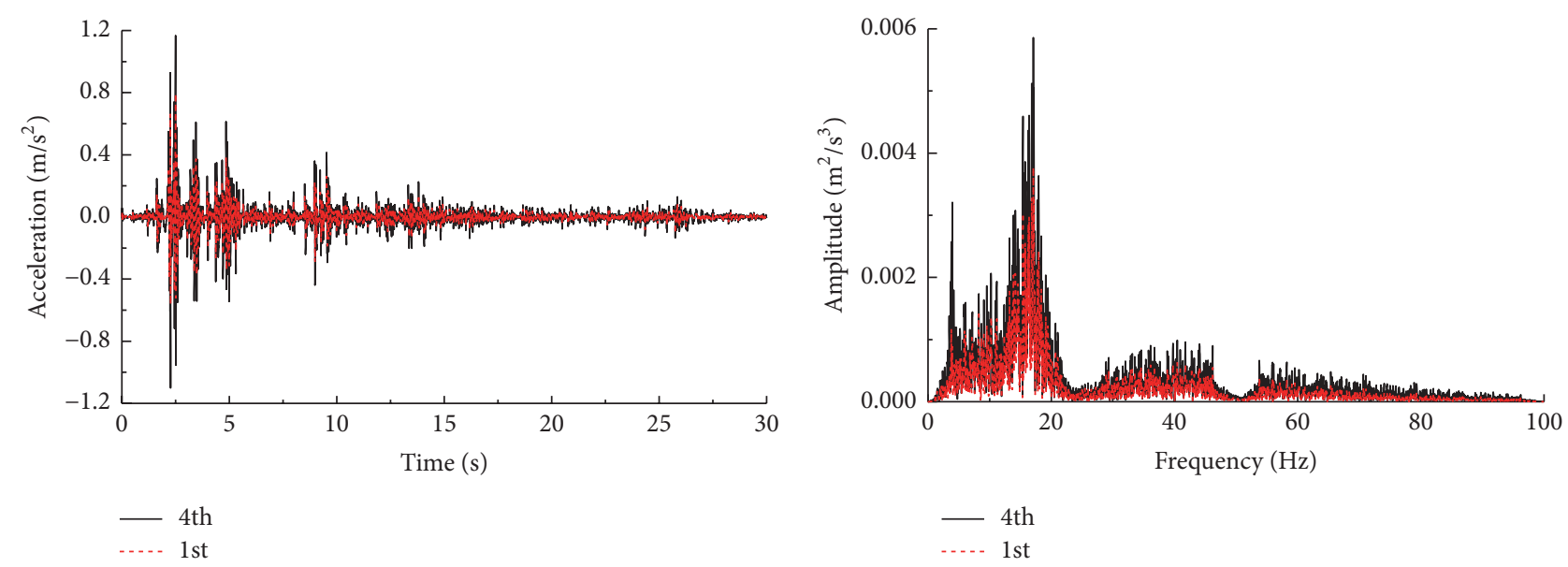

FIGURE 9: Vertical acceleration time history and corresponding Fourier spectrum curves at node 103 on the 4 th floor and node 18 on the 1 st floor under standard case (HV).

is mainly concentrated in low frequency, especially at the structure natural frequency $(1.958 \mathrm{~Hz})$, while the spectrum of the frequency for vertical acceleration is much wider than that of horizontal acceleration.

6.2. Floor Response Spectrum. Figure 10 reports the response spectrum curves of horizontal and vertical acceleration for the fourth and first floor. The predominant period of horizontal acceleration (as shown in Figure 10(a)) is much longer than that of the vertical acceleration (as shown in Figure 10(b)). From Figure 10, it is also found that, in lower floor, the predominant period is shorter, which is consistent with the result obtained from Figures 8 and 9.

6.3. Base Mat Vertical Displacement and Rotation. According to the prescribed method shown in Figure 4, the base mat will be separated from the underlying soil if the vertical displacement at node 1 (See Figure 4) is larger than zero. The uplifted time and its related uplifted amount can be seen in
Figure 11 for foundation corner. The peak vertical displacement at node 1 under the $\mathrm{HV}$ case is $0.334 \mathrm{~mm}$ with the trigger time at $2.4549 \mathrm{~s}$, and, accordingly, it can be calculated that the rotation angle of foundation is $0.334 / 12000$, which is so small that the influence of base mat uplift on seismic response of structure can be neglected. The above result can also be verified by the time history curves of horizontal acceleration and its corresponding Fourier spectrum curves for node 103 for the case of base mat uplift allowed and restricted (Figure 12). From Figure 12, it is found that for both cases the curves are almost identical.

6.4. Uplift Area Ratio. The ratio of uplift area is defined as the ratio of the maximum uplifted area to the total area of base mat. This value is a key parameter to evaluate the effect of base mat uplift on the seismic response of structure. In current study, the maximum uplifted area can be determined by the following procedures: (a) extract the time history curve of vertical displacement at node 1 ; (b) determine the trigger time 

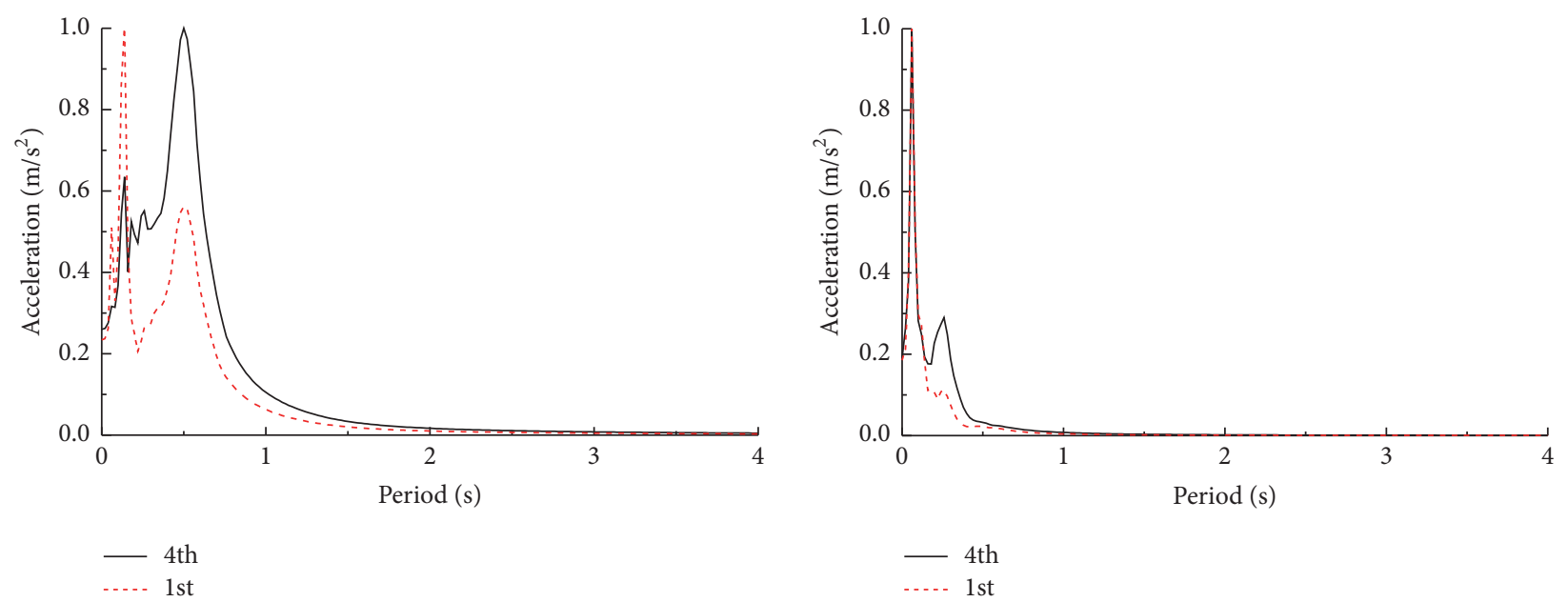

FIGURE 10: Horizontal and vertical acceleration response spectrum curves of the fourth and first floor under standard case (HV).

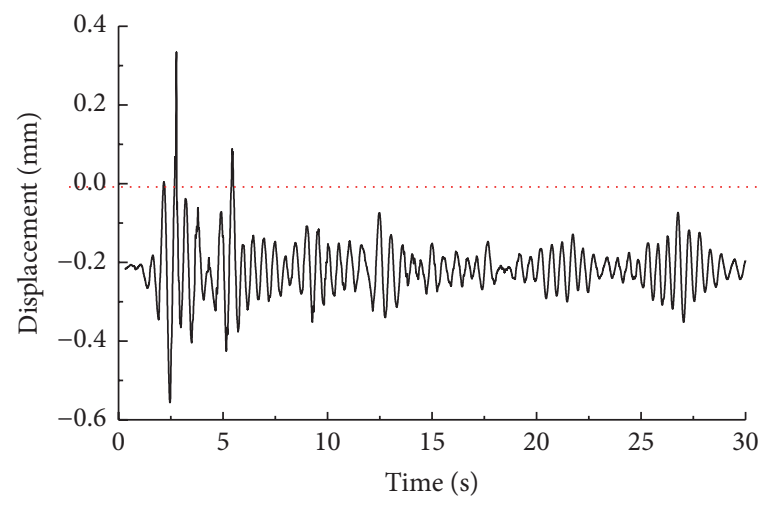

- $\mathrm{HV}$

FIgURE 11: Vertical displacement at the corner of base mat under standard case (HV).
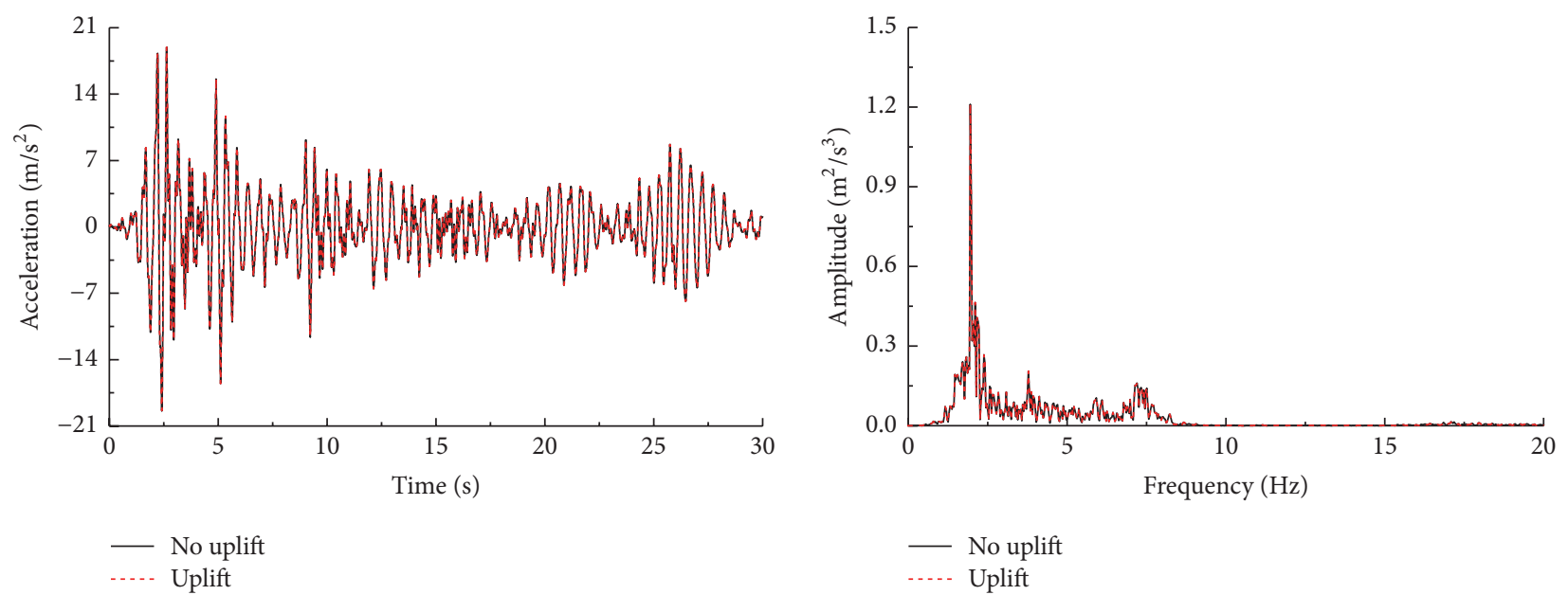

FIGURE 12: Horizontal acceleration time history and its Fourier spectrum curves at node 103 on the fourth floor under standard case (HV). 


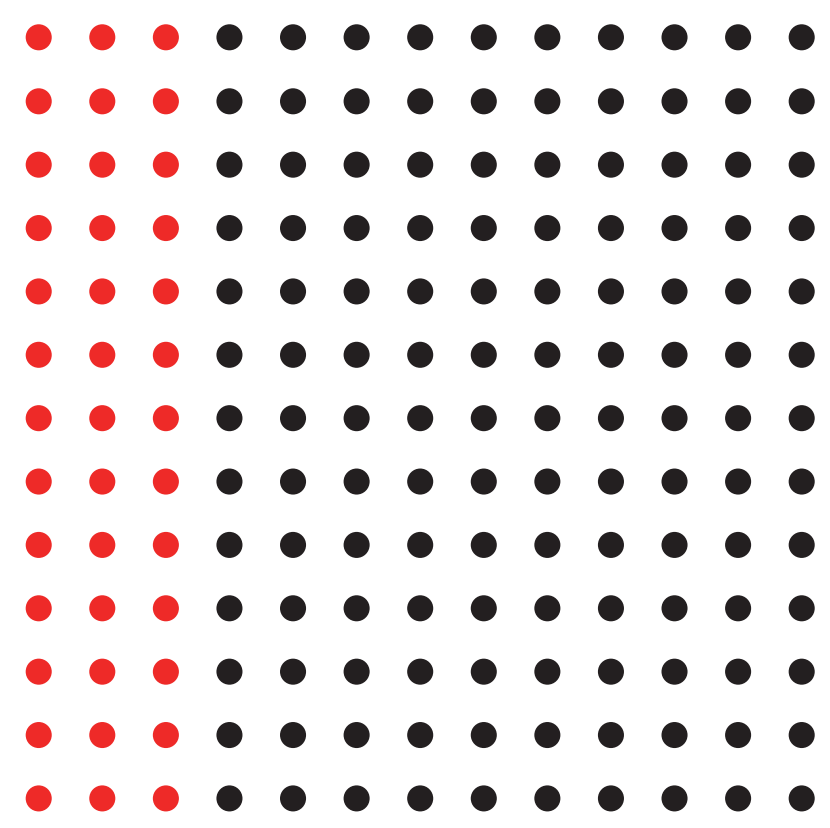

FIGURE 13: Schematic diagram of uplifted nodes under standard case: 52 nodes uplifted and uplift area ratio is $25.0 \%$.

of the base mat uplift; and (c) select the nodes whose vertical displacement is bigger than zero at this time or substep. These selected nodes are seen as the uplifted nodes and the area consisted by these nodes is then defined as the maximum uplifted area.

Figure 13 is the selected uplifted nodes at the base mat for the standard case (HV case). It can be observed that there are 52 uplifted nodes and hence the uplift area ratio is calculated as $25 \%$ for the HV case.

\section{Analysis of Influence Factors}

Key factors affecting the dynamic response of structure are analyzed in this section, including seismic wave (input direction, amplitude, and type), velocity of shear wave in soil, and structure related factors (stiffness and the ratio of height to width, $H / B$ ). The calculated results are compared with those of the standard case (HV case). For the sake of simplicity, the $\mathrm{H}$ case represents the one that the structure is merely excited in horizontal direction.

7.1. Influence of Input Seismic Wave Directions. Figure 14 shows the time history curve of horizontal acceleration and its corresponding Fourier spectrum curves at node 103 both for the $\mathrm{H}$ case and the HV case. It can be seen that the horizontal acceleration and spectrum curves for both cases are almost the same, which means the seismic wave input at vertical direction has little impact on the structural response at horizontal direction.

From Figure 15, it is found that the vertical acceleration is greater in $\mathrm{HV}$ case than that in the $\mathrm{H}$ case. The higher frequency contents are observed for the HV case due to the base mat uplift as shown in Figure 16.
Figure 17 illustrates the horizontal and vertical acceleration response spectrum curves at node 103 on the fourth floor for $\mathrm{HV}$ and $\mathrm{H}$ cases.

Figure 18 is the time history curves of vertical displacement at node 1 (see Figure 4) for the HV and $\mathrm{H}$ cases. It can be seen that the variation of vertical displacement response under two cases is identical, and there are only small difference in peak values for both cases. It is found that the peak value for the $\mathrm{H}$ case is $0.189 \mathrm{~mm}$ at time of $2.4089 \mathrm{~s}$, while the peak value for $\mathrm{HV}$ case is $0.334 \mathrm{~mm}$ at the time of $2.4549 \mathrm{~s}$, which is almost twice of that in the $\mathrm{H}$ case.

Figures 19 and 13 are the uplifted nodes at the base mat for $\mathrm{H}$ case and $\mathrm{HV}$ case, respectively. It can be seen that there are 39 uplifted nodes and the uplift area ratio is about $16.7 \%$, while for $\mathrm{HV}$ case the uplift area ratio is $25 \%$.

Based on above analysis, it can be concluded that the seismic wave input at vertical direction has little influence on structural response at horizontal direction, while mainly having impact on the structural response at vertical direction and the maximum base mat uplift area ratio.

7.2. Influence of Input Seismic Wave Amplitudes. The maximum vertical displacements at node 1 for the $\mathrm{HV}$ case with amplitudes of $0.15 \mathrm{~g}, 0.5 \mathrm{~g}$, and $1 \mathrm{~g}$ are $-0.42 \mathrm{~mm}, 0.334 \mathrm{~mm}$, and $2.91 \mathrm{~mm}$, respectively, and its corresponding maximum uplift area ratios are determined as $0 \%, 25 \%$, and $75 \%$, respectively. It can be seen that the maximum vertical displacement at base mat is negative in the case that the amplitude of seismic wave is small $(0.15 \mathrm{~g})$, which means the base mat uplift does not occur. Meanwhile, for the HV case with the amplitude of $0.4 \mathrm{~g}$, the maximum vertical displacement at node 1 is found to be $0.02 \mathrm{~mm}$, which can be treated as the critical amplitude for the base mat uplift in current study.

7.3. Influence of Input Seismic Wave Types. It is well known that the different seismic waves have different frequency components and in turn generate different seismic responses of structure. In this section, three types of seismic waves are selected with consideration of the distance effect, that is, the EL wave (near-field wave), Taft wave (middle-distance wave), and Songpan wave (long-distance wave) which is recorded during the Wenchuan earthquake in 2008 in China. Their acceleration time history and Fourier spectrum curves are shown in Figure 7.

Due to the difference in computational times (EL wave $30 \mathrm{~s}$, Taft wave $50 \mathrm{~s}$, and Songpan wave $150 \mathrm{~s}$ ), the results from different seismic waves are shown separately. Figures 8,20 , and 21 show the time history curve of horizontal acceleration and its corresponding Fourier spectrum curves at node 103 under EL, Taft, and Songpan waves (with HV input), respectively. It can be seen that for Songpan wave the acceleration has bigger value $(22.09 \mathrm{~m} / \mathrm{s} 2)$ while the acceleration for Taft wave is smaller $(18.44 \mathrm{~m} / \mathrm{s} 2)$. This is reasonable as the dominant frequency of Songpan wave is about $2 \mathrm{~Hz}$ (as shown in Figure 7), which is very close to structural first natural frequency of $1.96 \mathrm{~Hz}$. And from Table 4, it is observed that the first-order vibration mode for structure is horizontal vibration. 

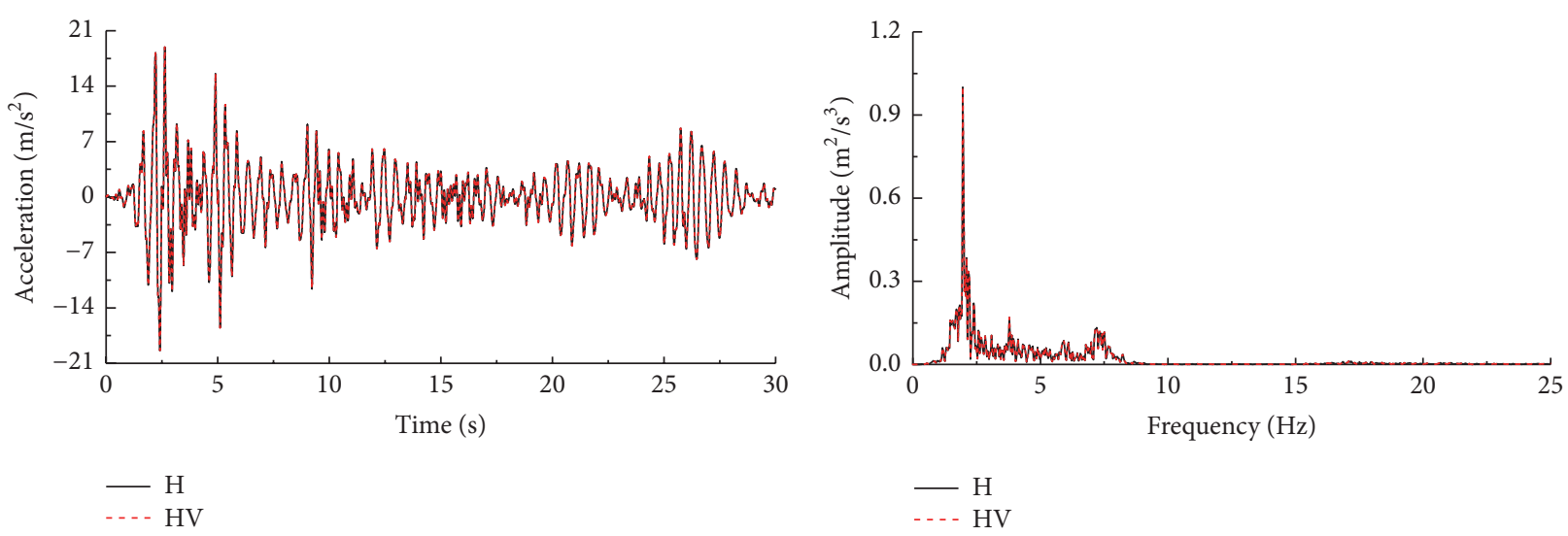

FIgURE 14: Horizontal acceleration time history and spectrum curves at node 103 under EL wave for $\mathrm{H}$ and $\mathrm{HV}$ case.
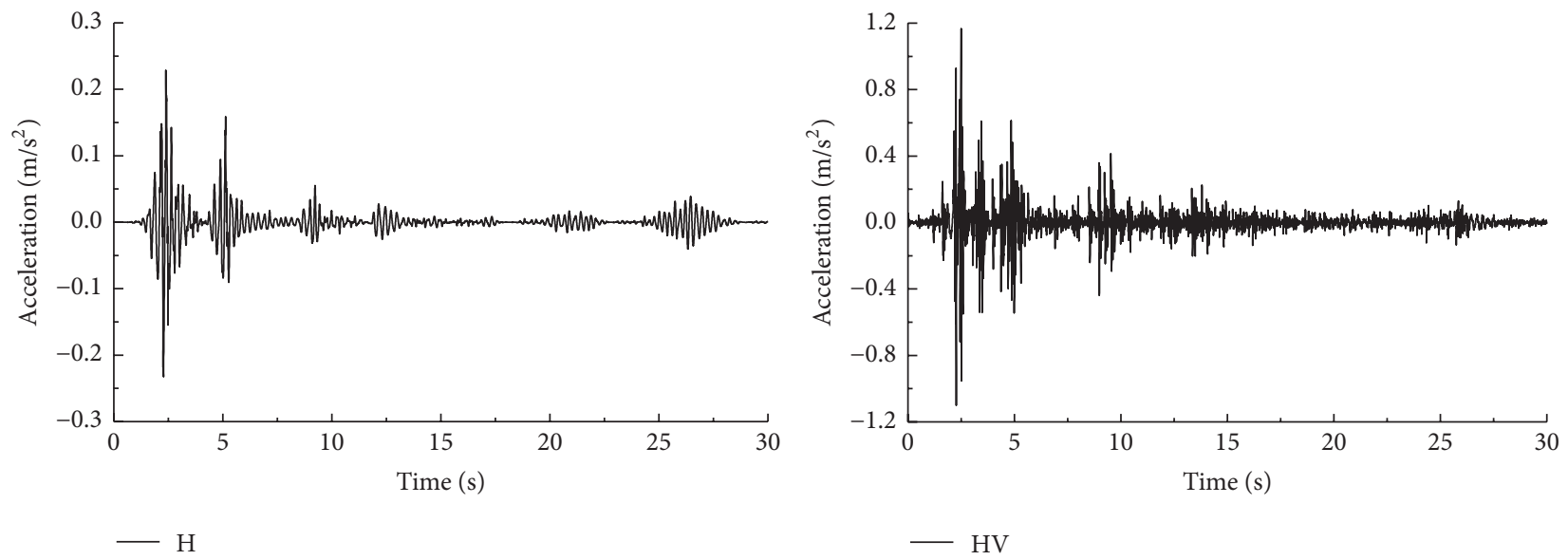

FIGURE 15: Vertical acceleration time history at node 103 under EL wave for $\mathrm{H}$ case and HV case.

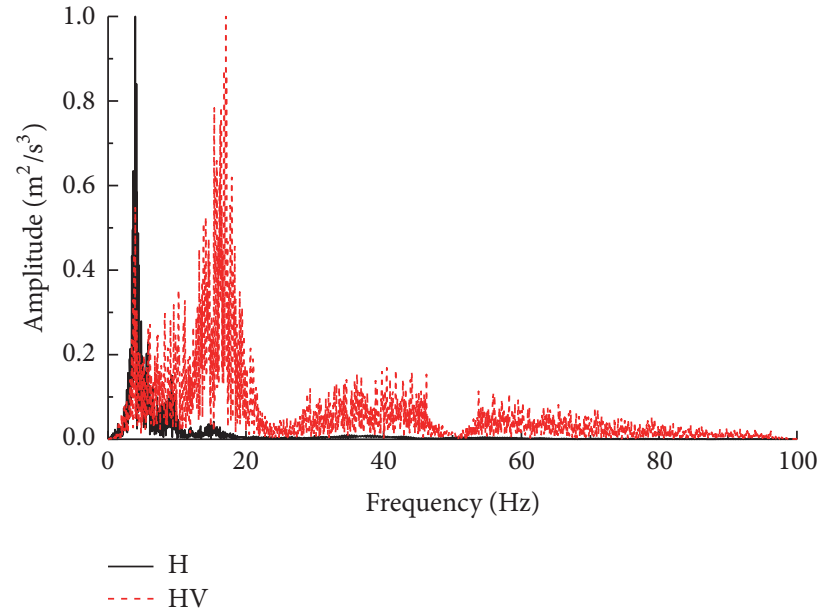

FIGURE 16: Normalized vertical acceleration Fourier spectrum curves at node 103 under EL wave for $\mathrm{H}$ case and HV case.

The vertical displacement response at node 1 (Figure 22) under Songpan wave has bigger value of $0.436 \mathrm{~mm}$, while, for the Taft wave, smaller value is observed $(0.0488 \mathrm{~mm})$, which is only one-tenth of that in the case of Songpan wave. However, more importantly, based on the red dotted line in Figure 22, it is found that the vertical displacements under the EL and Taft wave exceeded zero value at several moments, while for Songpan wave, the vertical displacement went beyond zero value at concentrated moments. It can be postulated that under Songpan wave the base mat uplift occurs at concentrated moment, while base mat uplift happens at several moments under the EL and Taft wave.

Figures 23, 24, and 25 report the time history curve of vertical acceleration and its corresponding Fourier spectrum curves at node 103 for the case of EL, Taft, and Songpan waves with the standard HV input wave, respectively. It can be seen that the acceleration under Songpan wave is bigger while the acceleration under EL wave is smaller. From the figure, it is also observed that the Fourier spectrum curve under Songpan wave consists of many higher frequency components between $40 \mathrm{~Hz}$ and $100 \mathrm{~Hz}$, at which the bigger uplift displacement occurred.

Figures 13, 26, and 27 give the schematic diagrams of uplifted nodes under EL, Taft, and Songpan wave with the standard HV input, respectively. From Figure 27, it is found that the maximum uplifted area ratio under Songpan wave 

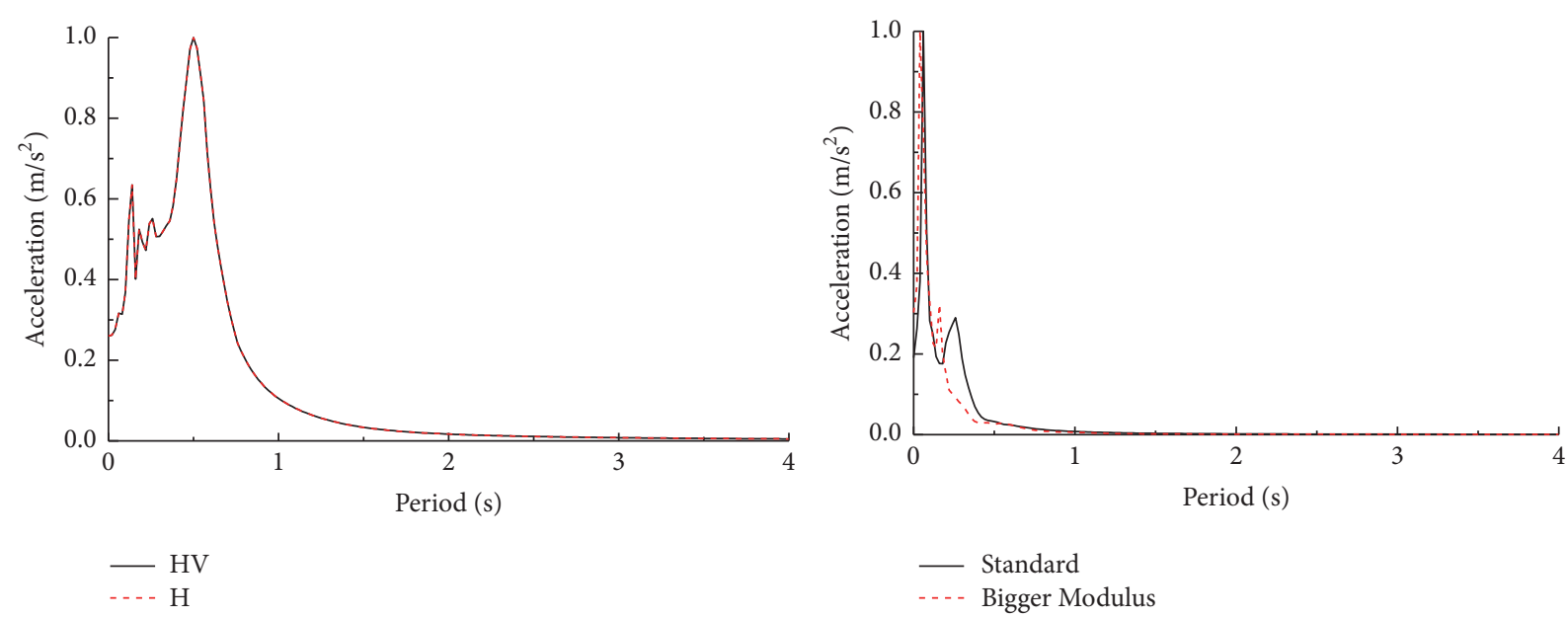

FIGURE 17: Normalized horizontal and vertical acceleration spectrum curves at node 103 under EL wave for HV and H case.

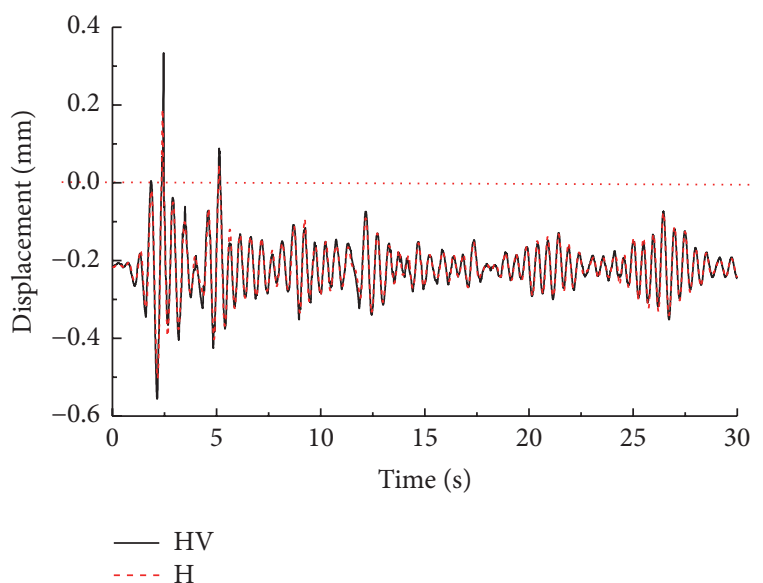

Figure 18: Vertical displacement time history curves at node 1 under $\mathrm{EL}$ wave for $\mathrm{H}$ case and $\mathrm{HV}$ case.

has a bigger value of $25.6 \%$, while the ratio under Taft wave is as small as $5.6 \%$.

From the above analysis, it can be concluded that the different seismic waves have a significant influence on the dynamic response of structure due to different frequency components from each seismic wave. When the predominant frequency of seismic wave is closer to that of the natural frequency of structure, the seismic response of structure will be excited significantly.

7.4. Influence of Shear Wave in Soil. Figures 28, 13, and 29 illustrate the schematic diagrams of uplifted nodes under the EL wave with the velocity of shear wave in soil of $400 \mathrm{~m} / \mathrm{s}$, $1100 \mathrm{~m} / \mathrm{s}$, and $2000 \mathrm{~m} / \mathrm{s}$, respectively. The maximum uplifted area ratios under the above three velocities are found to be $5.6 \%, 25 \%$, and $33.3 \%$, respectively, which means that the stiffer the soil, the easier the occurrence of the base mat uplift.

7.5. Influence of Structure Stiffness. Two cases were considered in this section. For the first case, the stiffness of the

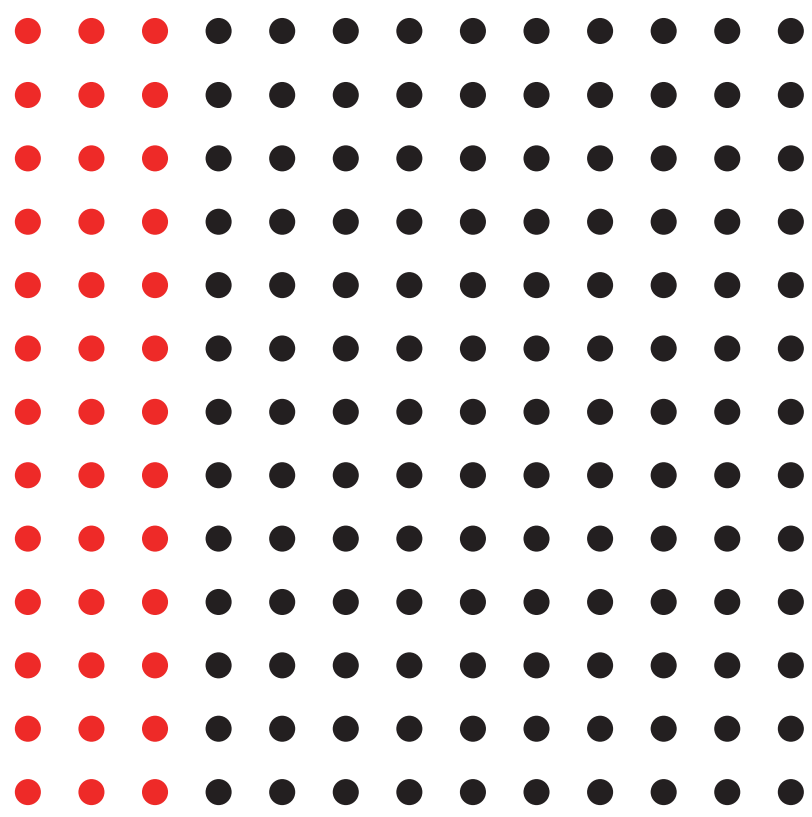

FIGURE 19: Schematic diagram of uplifted nodes under H case: 39 nodes uplifted and uplift area ratio is $16.7 \%$.

structure is increased: the thickness of side wall is increased from $0.2 \mathrm{~m}$ to $0.4 \mathrm{~m}$, and the section of the column is enhanced from $0.6 \mathrm{~m} * 0.6 \mathrm{~m}$ to $1.0 \mathrm{~m} * 1.0 \mathrm{~m}$. Consequently, the structural natural frequency is increased from $1.958 \mathrm{~Hz}$ to $3.033 \mathrm{~Hz}$. For simplicity, this case is labeled as Bigger Section. Figure 30 reports the time history curve of vertical displacement at node 1 on the base mat for the Bigger Section case. It can be found that the vertical displacement is less than zero during all time, which means that the base mat was not uplifted during the earthquake. This is because that the increase of structural section size will significantly increase the total mass of the structure, and in turn the heavier weight of structure will be beneficial to resist the occurrence of base mat uplift. For the second case, in order to investigate 

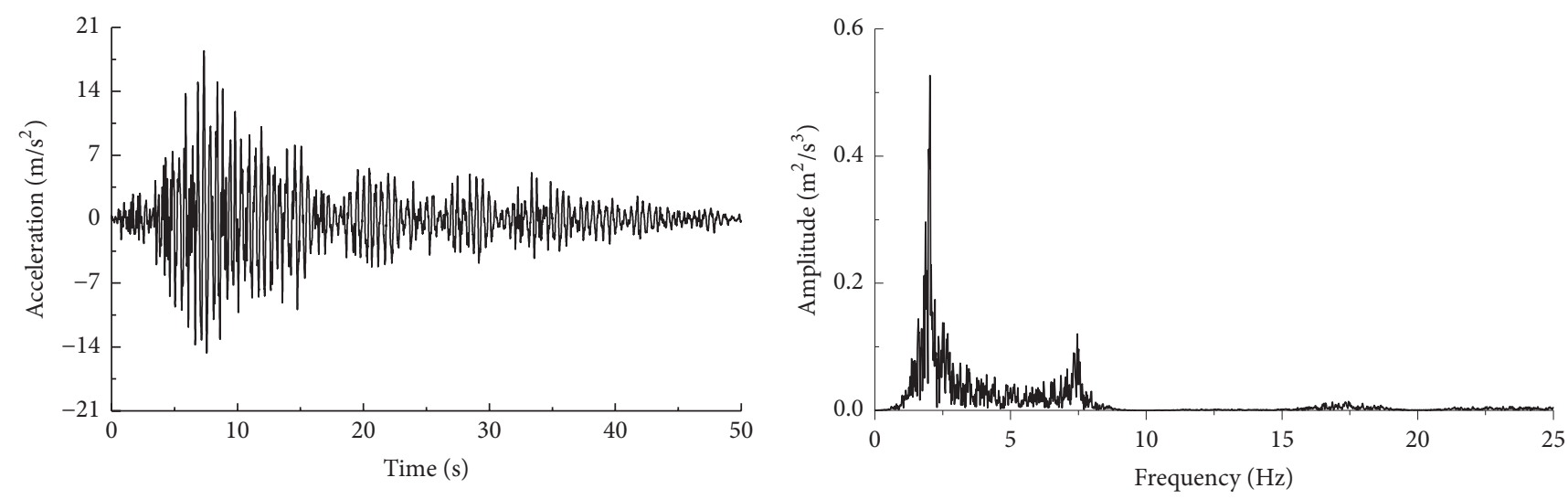

FIgURE 20: Horizontal acceleration time history and Fourier spectrum curves at node 103 under Taft wave (HV case).
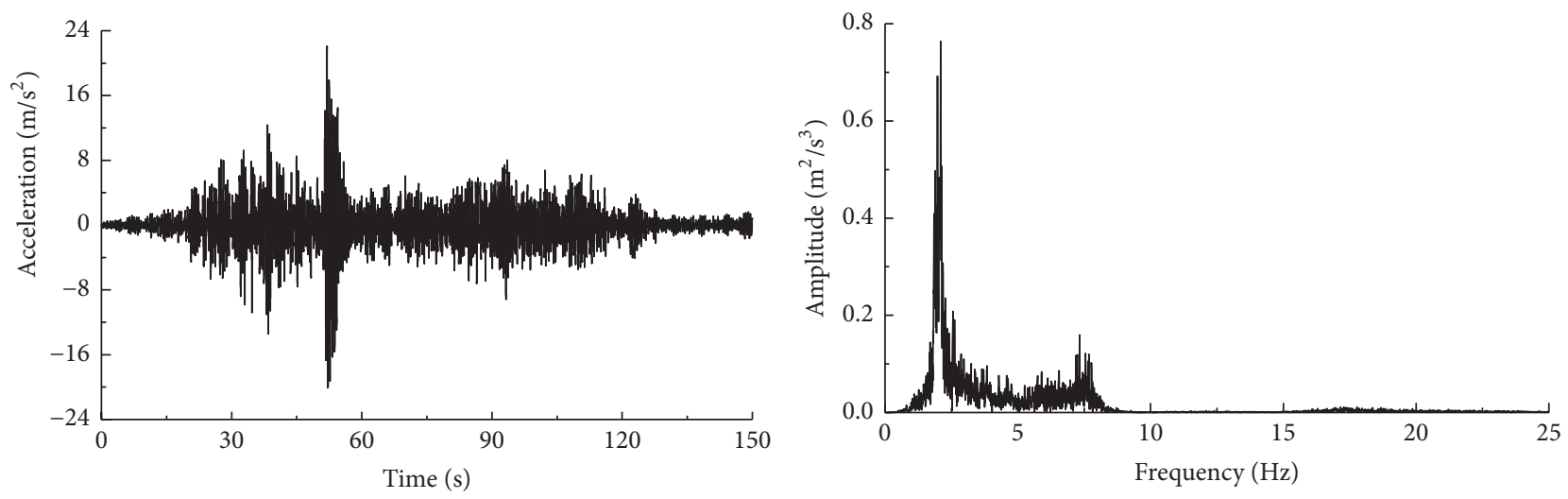

- Songpan

FIGURE 21: Horizontal acceleration time history and Fourier spectrum curves at node 103 under Songpan wave (HV case).
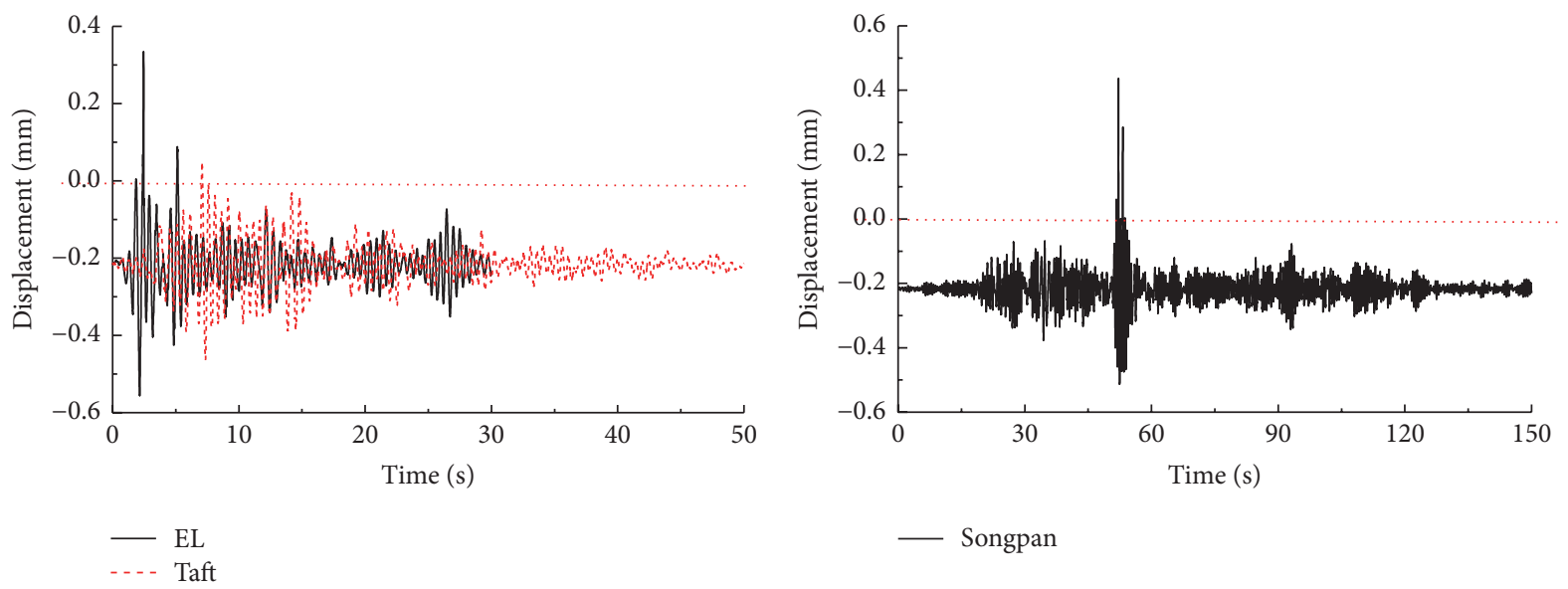

FIGURE 22: Comparison of vertical displacement time history curves at node 1 under EL, Taft, and Songpan waves.

the influence of structure stiffness on the dynamic response of structure, the total structural mass remains unchanged, while the structural stiffness is strengthened by increasing material modulus. In this case, the modulus of material is set to $75 \mathrm{GPa}$ after using trial and error method to make the natural frequency of structure close to that in the first case.
The second case is labeled as Bigger Modulus. From Figure 30, it is found that the base mat uplift occurs. Hence, it can be concluded that the base mat is easier to occur under bigger structural stiffness.

The spectrum curves of horizontal and vertical acceleration at node 103 on the fourth floor for Standard and Bigger 


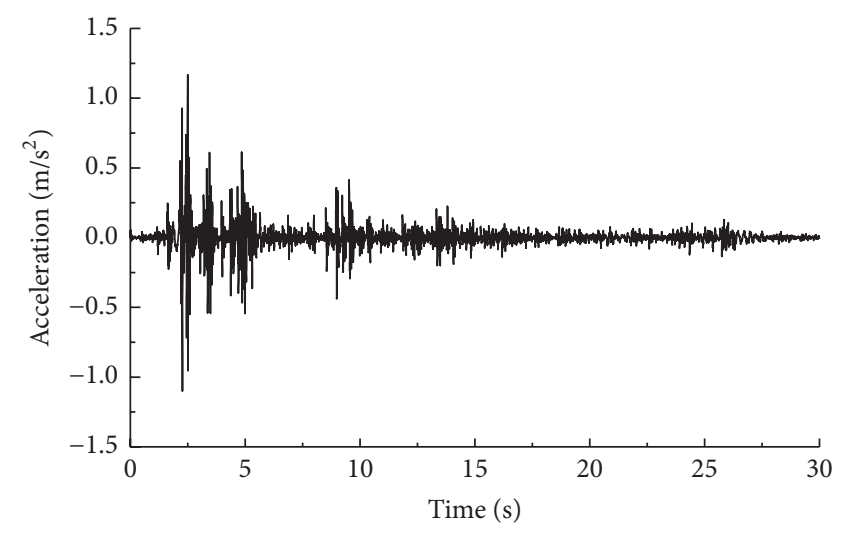

- EL

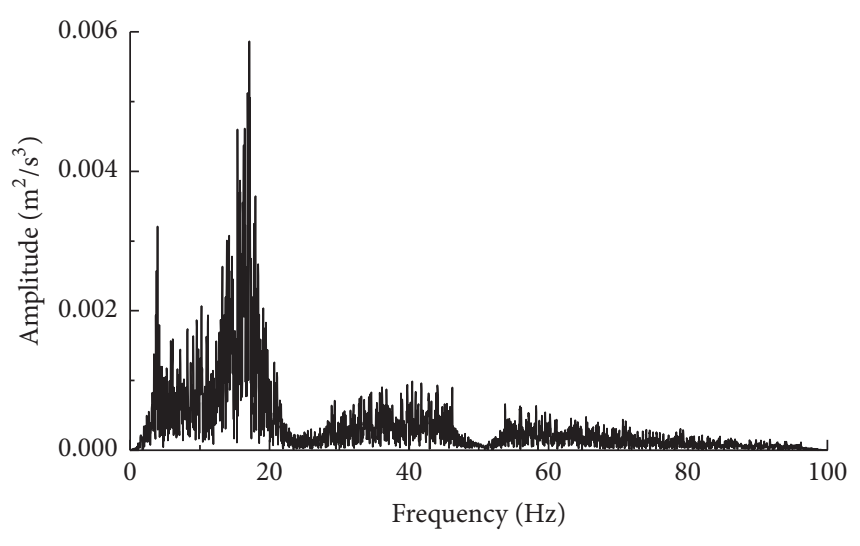

- EL

FIgURE 23: Vertical acceleration time history and Fourier spectrum curves at node 103 under EL wave (HV case).
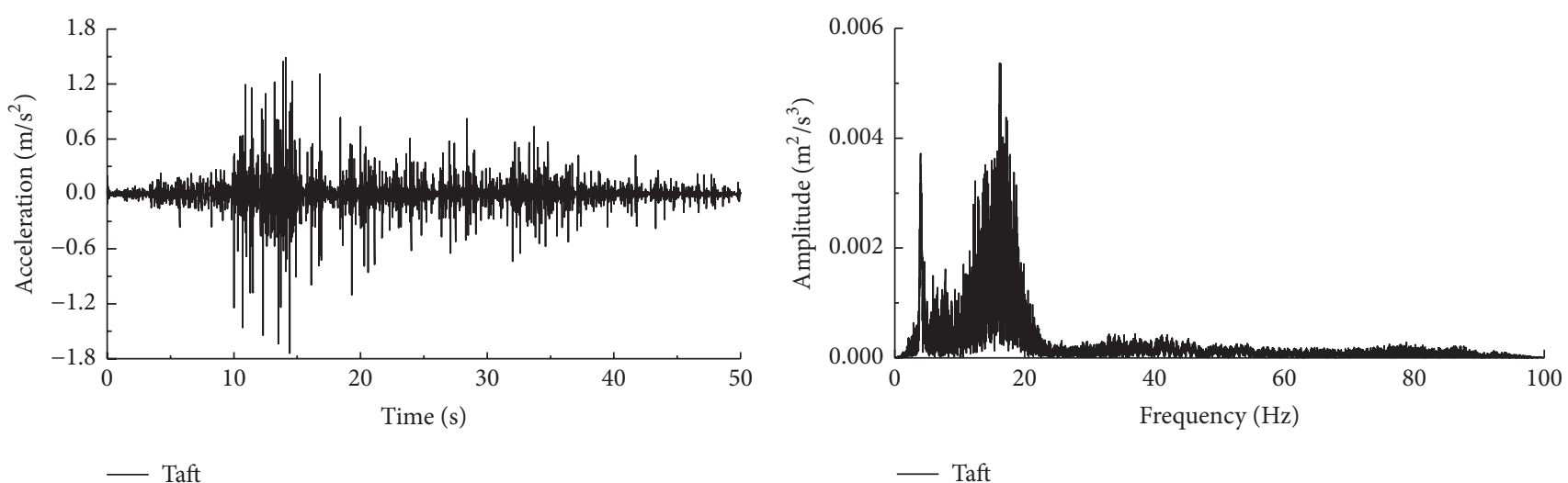

FIGURE 24: Vertical acceleration time history and Fourier spectrum curves at node 103 under Taft wave.

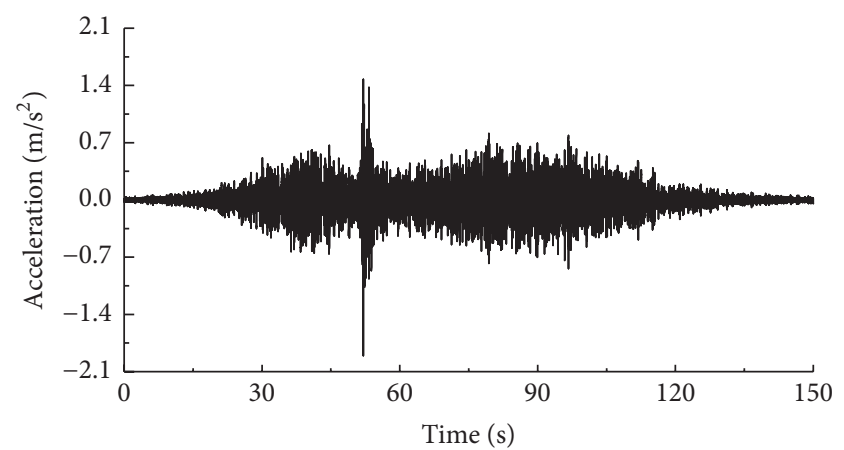

- Songpan

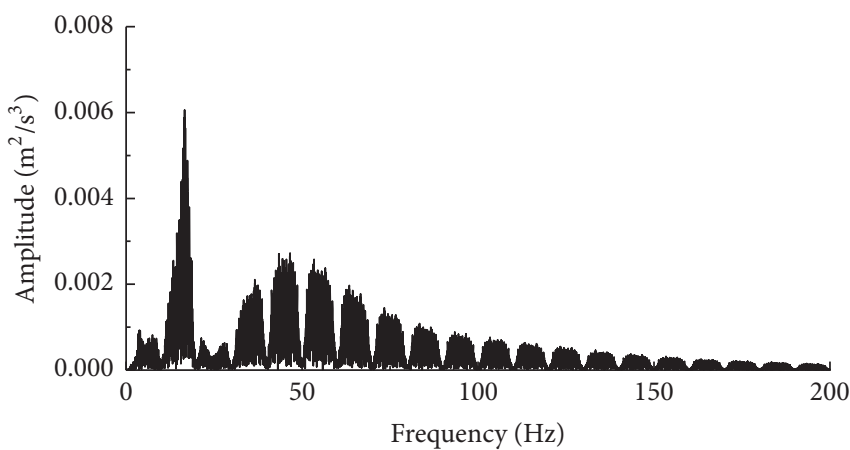

- Songpan

FIgURE 25: Vertical acceleration time history and Fourier spectrum curves at node 103 under Songpan wave.

modulus case are given in Figure 31. From the figure, it can be found that the structural stiffness affects the horizontal acceleration in shorter period, while it impacts on the vertical acceleration in longer period.

The schematic diagram of uplifted nodes under the case of Bigger Modulus is given in Figure 32. It can be seen that only 34 nodes were uplifted and then the maximum uplift area ratio is found to be $12.5 \%$, which is much smaller than that in standard case (52 uplifted nodes with the maximum uplift area ratio of 25\%).
7.6. Influence of the Ratio of Structure Height to Width. The ratio of structural height to width $(H / B)$ is set to 1 in the standard case. In this section, the values for $H / B$ are set to 0.5 and 2 by modifying the structure to two-story and eight-story, respectively. And other material parameters remain the same as those in Standard case. The time history curves of vertical displacement for two $H / B$ values are given in Figure 33. It is observed that the base mat uplift did not occur for these two cases; however, the base mat uplift is relatively easier to occur for smaller $H / B$ value. 


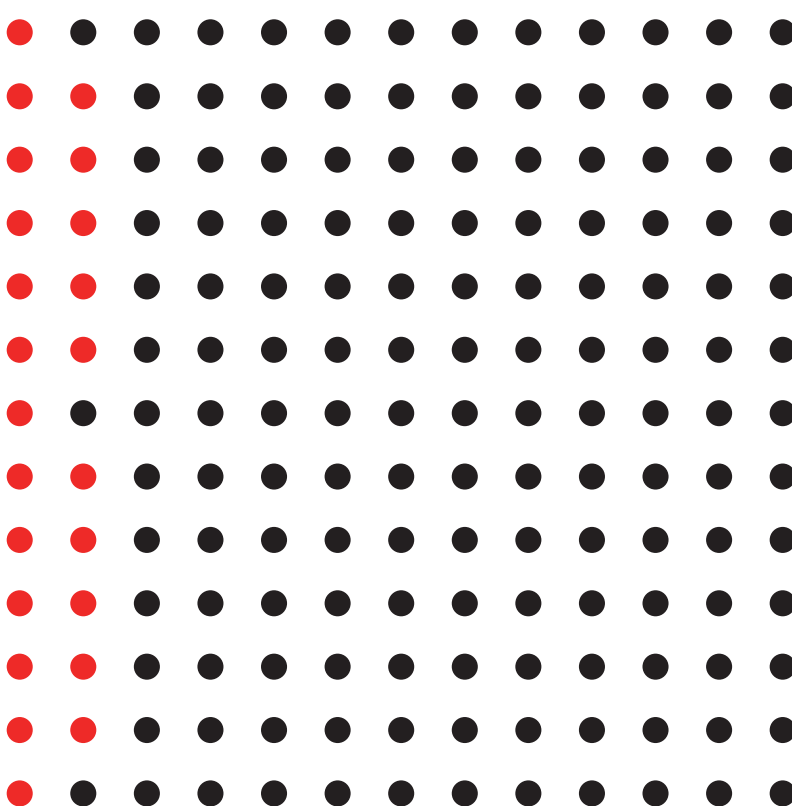

FIGURE 26: Schematic diagram of uplifted nodes under Taft wave for HV case (23 nodes uplifted and uplift area ratio is 5.6\%).

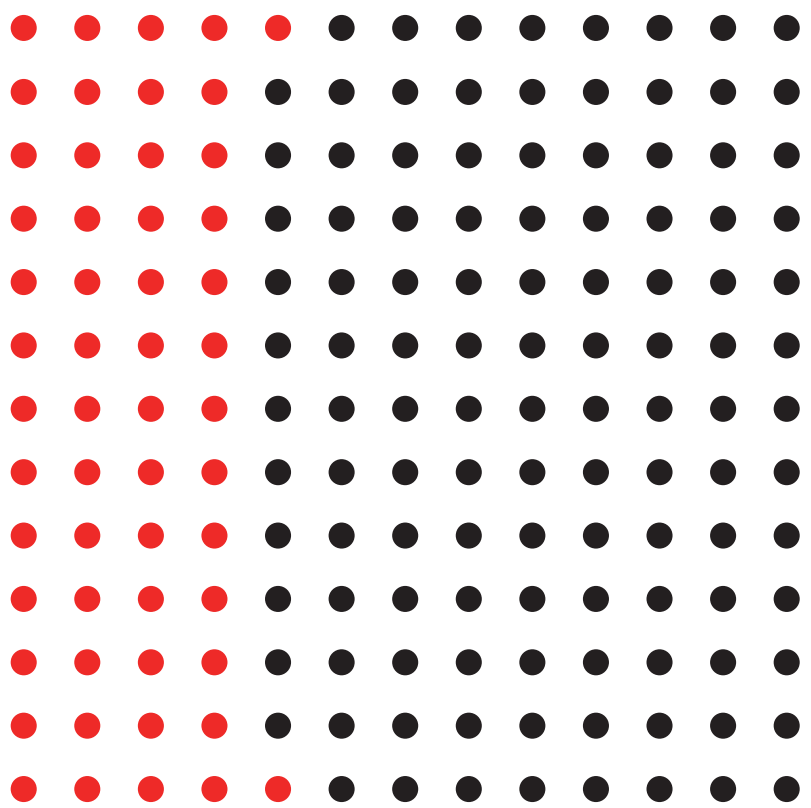

FIGURE 27: Schematic diagram of uplifted nodes under Songpan wave for HV case (54 nodes uplifted and uplift area ratio is 25.6\%).

The comparisons of the structural natural frequency and its related structural stiffness are also conducted. The first natural frequencies for $H / B$ values of 2,1 , and 0.5 are found to be $0.851 \mathrm{~Hz}, 1.958 \mathrm{~Hz}$, and $4.746 \mathrm{~Hz}$, respectively, and their related masses are $1.363 e 6 \mathrm{Kg}, 7.375 e 5 \mathrm{Kg}$, and $4.249 e 5 \mathrm{Kg}$, respectively. Therefore, based on the empirical formula $k=$ $m *(2 \pi f)^{2}$, the corresponding structural stiffness for different $H / B$ values can be calculated as $3.9 e 7 \mathrm{~N} / \mathrm{m}, 11.16 e 7 \mathrm{~N} / \mathrm{m}$, and $37.79 e 7 \mathrm{~N} / \mathrm{m}$, respectively. It is obvious that with the increase

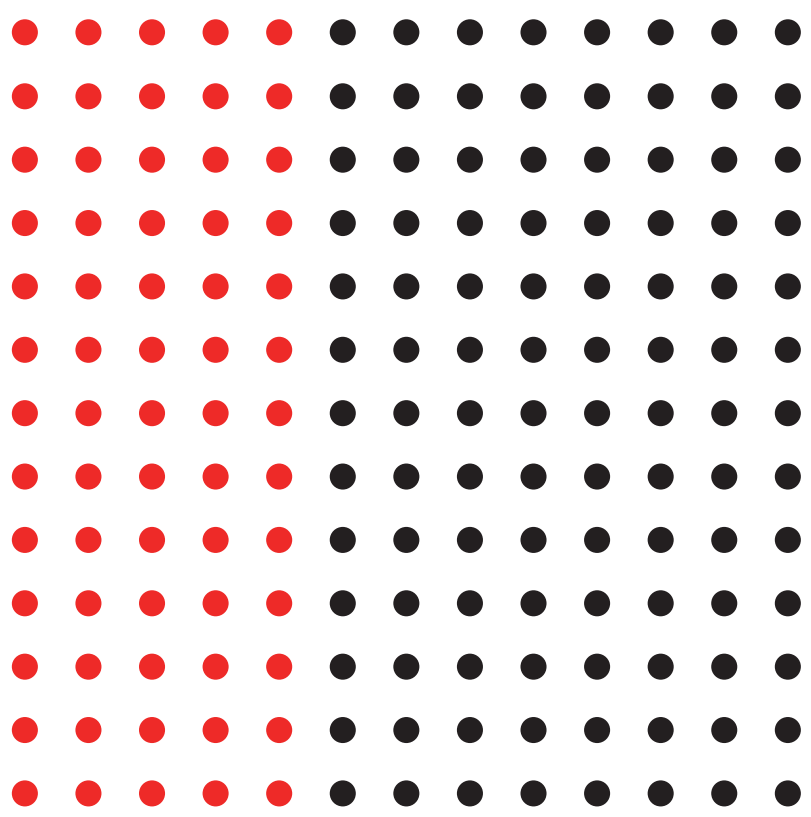

FIGURE 28: Schematic diagram of uplifted nodes with the soil shear wave $2000 \mathrm{~m} / \mathrm{s}$ under EL wave for HV case (65 nodes uplifted and uplift area ratio is $33.3 \%$ ).

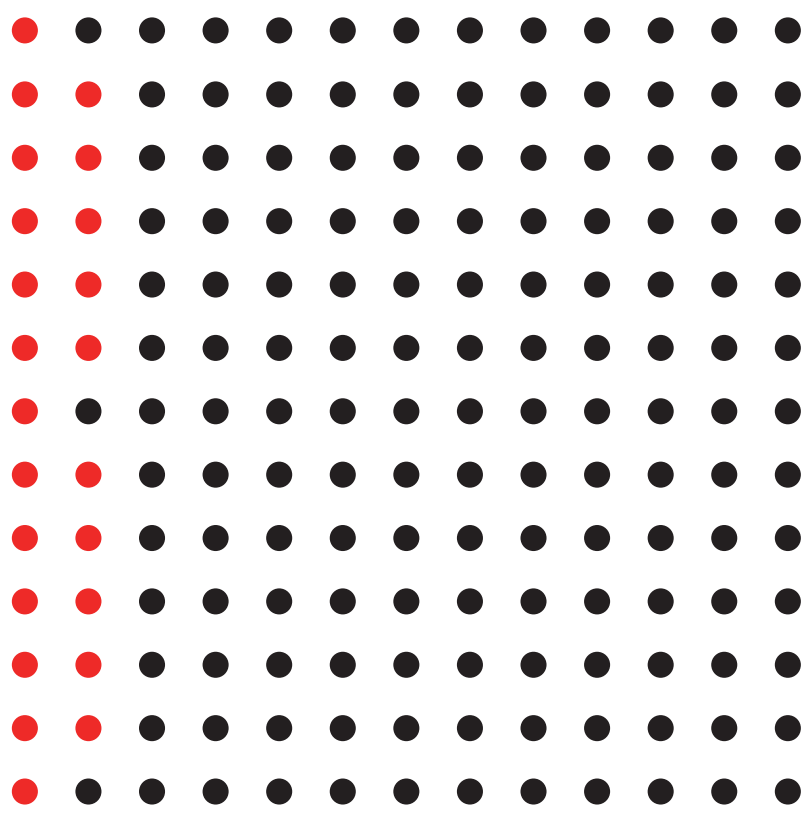

FIGURE 29: Schematic diagram of uplifted nodes with the soil shear wave $400 \mathrm{~m} / \mathrm{s}$ under El wave for HV case (23 nodes uplifted and uplift area ratio is $5.6 \%$ ).

of $H / B$ ratio, the structural masses increase while the firstorder natural frequency decreases. It is then postulated that the structure tended to be softer with the increase of $H / B$ ratio.

The base mat uplift is found easier to occur for small $H / B$ ratio value by comparing the case of $H / B$ ratio of 0.5 and 2 , while the conclusion is contrary by comparing the case of $H / B$ ratio of 0.5 and 1 . This can be explained in two aspects: 


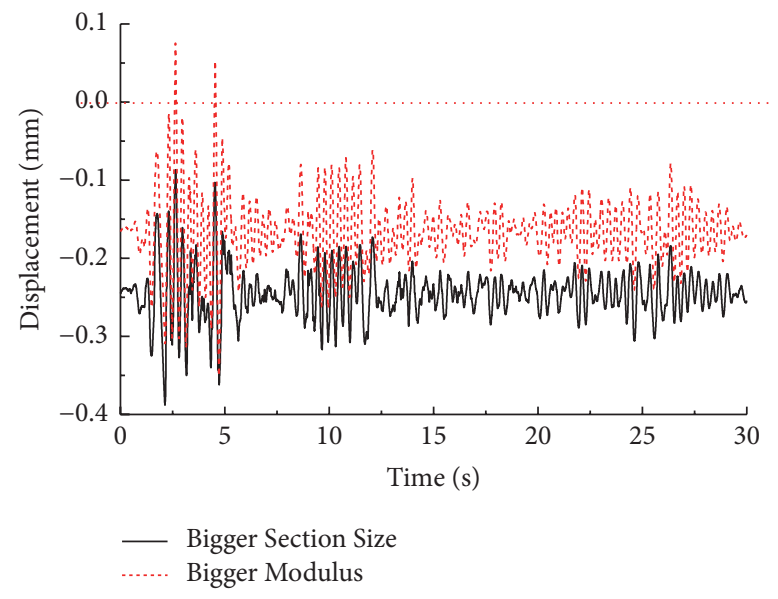

FIGURE 30: Vertical displacement time history curves at node 1 on the structure base mat under two cases: Bigger Section Size case and Bigger Modulus case.

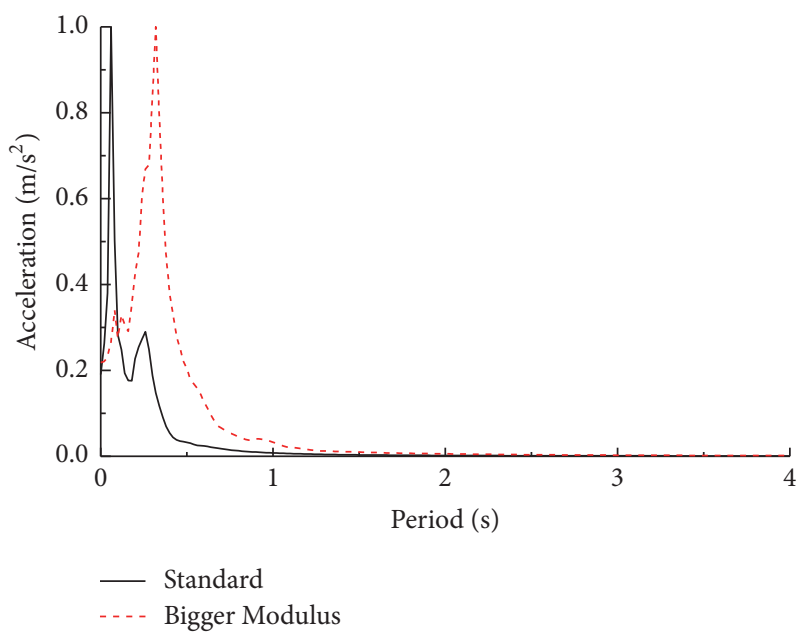

(a) Horizontal acceleration

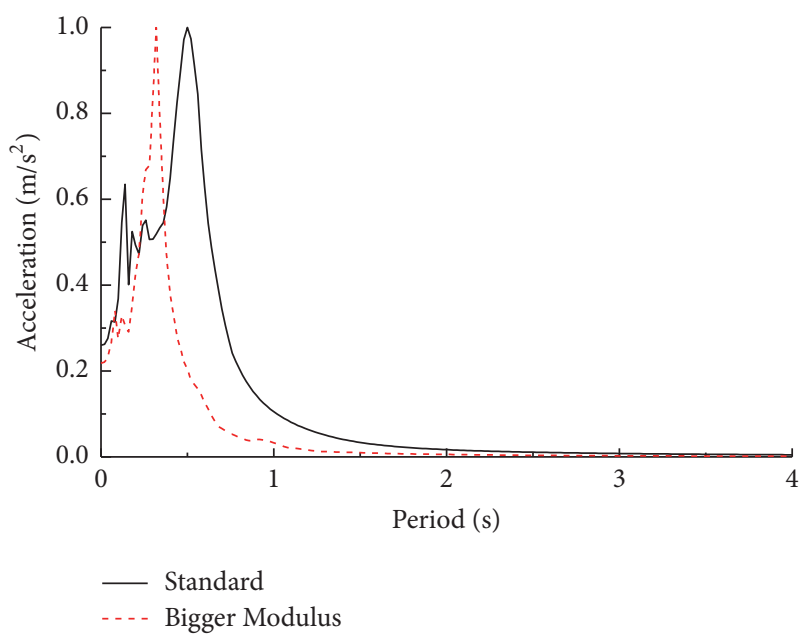

(b) Vertical acceleration

FIGURE 31: Spectrum curves of horizontal and vertical acceleration at node 103 under standard case and Bigger Modulus case.

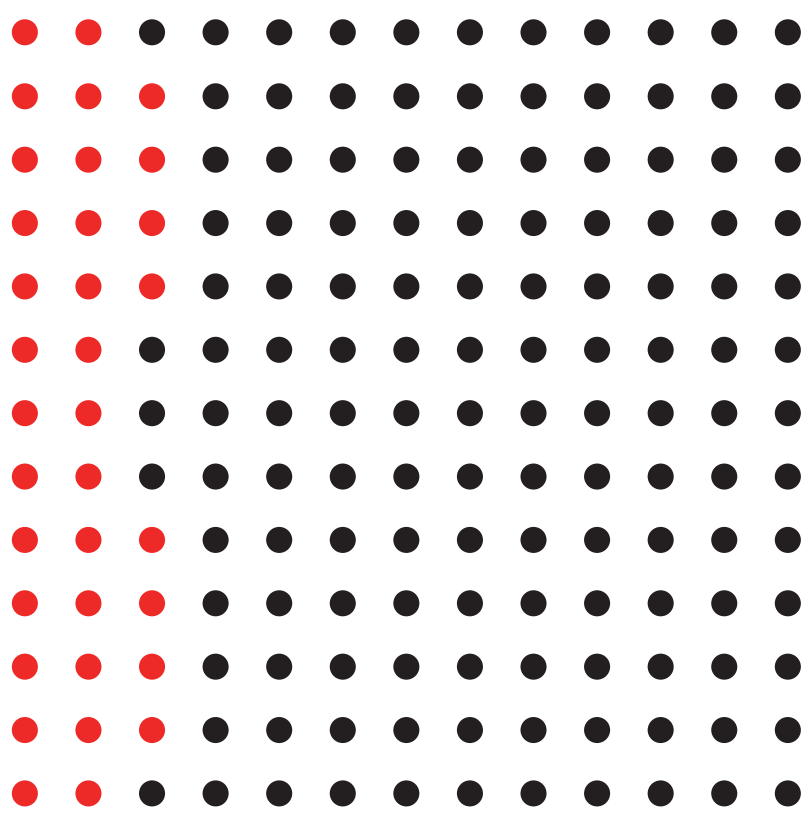

FIGURE 32: Schematic diagram of uplifted nodes under the Bigger Modulus case (34 nodes uplifted and the maximum uplift area ratio is $12.5 \%$ ).

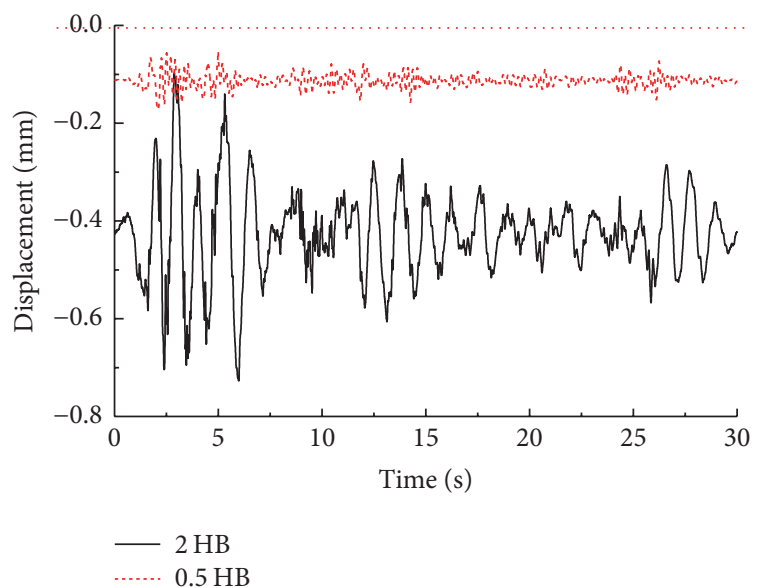

FIGURE 33: Vertical displacement time history curves at node 1 on the structure base mat under two cases: structure $H / B$ ratios are equal to 0.5 and 2 .

firstly, the bigger inertial force and overturning moment tend to be generated for higher structure and then result in the uplifting of base mat. Secondly, it is well known that the structure will perform more stable for larger width, which is beneficial to resist the occurrence of base mat uplift.

7.7. Influence of the Concentrated Mass. It should be noted that the existence of the machine, furniture, or accessory equipment can be simplified as a concentrated mass on the floor in general. Theoretically, the influence of concentrated mass on the base mat uplift should be investigated in three aspects: firstly, greater inertial force will be applied on the structure, and hence the base mat uplift is easier to 


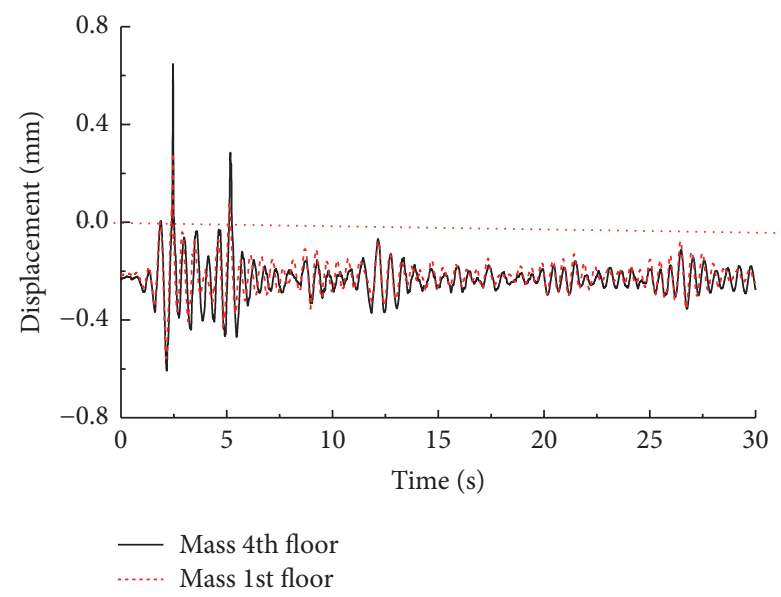

FIgURE 34: Vertical displacement time history curves at node 1 on the structure base mat under two cases: concentrated mass located on the fourth and first floor.

occur. Secondly, the concentrated mass has little influence on structural stiffness, and then the heavier structure can prevent base mat uplift. Thirdly, the structure will be assumed to be an unsymmetrical structure and then the torsion force will affect the dynamic response of structure. However, the effect of torsion force is decided by the weight of the concentrated mass. This means whether the base mat uplift can be prevented or not is determined by the weight and location of the concentrated mass. However, the influence of the location of concentrated mass is discussed in this section because the weight can be changed a lot in the practical situation.

A concentrated mass with the one-tenth of the total weight of the structure is located on the middle point in the fourth and the first floor, respectively. The time history curves of vertical displacement for the two cases are shown in Figure 34. It is observed that the maximum vertical displacements for the Mass on 4th Floor and Mass on 1st Floor are about $0.647 \mathrm{~mm}$ and $0.2836 \mathrm{~mm}$, respectively, and its corresponding maximum uplift ratios are found be to be $33.3 \%$ (65 uplifted nodes as shown in Figure 35) and 22.2\% (49 uplifted nodes as shown in Figure 36), respectively, while, for the standard case (No Concentrated Mass), the maximum vertical displacement is found to be $0.334 \mathrm{~mm}$ with the maximum uplift ratio of $25 \%$ (52 uplifted nodes). It can be found that the location of concentrated mass on the higher floor (4th floor) tends to make the base mat uplift easier to occur, while the existence of concentrated mass on the lower floor (1st floor) will prevent the base mat uplift. The final result depends on which factor is dominant: the overturning moment caused by inertial force or structure total weight.

\section{Conclusions}

In order to overcome the computational convergence issue in traditional contact and joint element method, a new method based on the spring element is proposed in this paper to consider the impact of base mat uplift on the seismic response

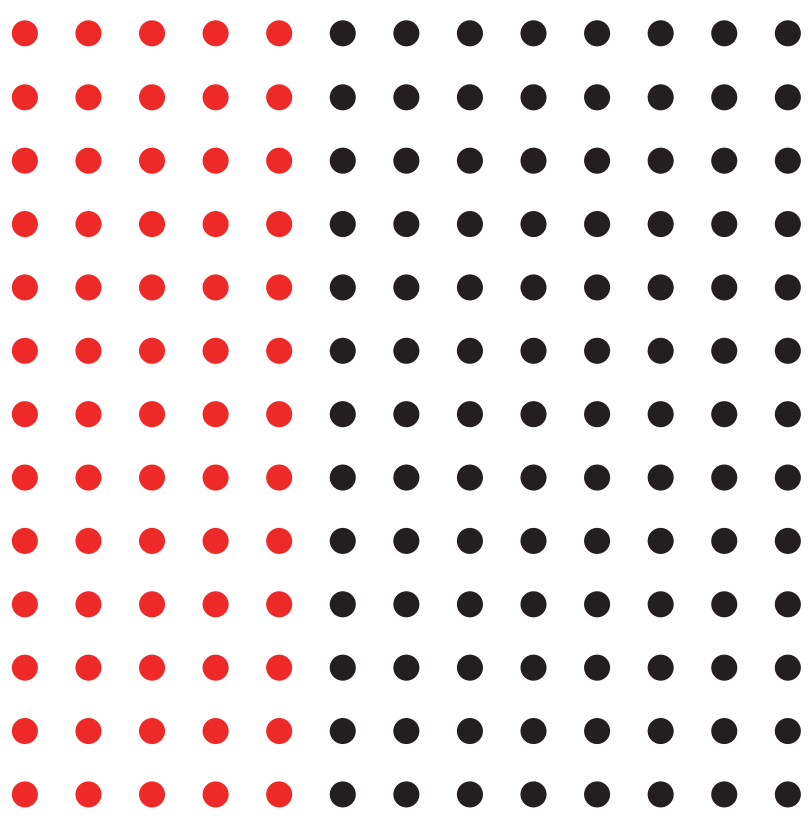

FIGURE 35: Schematic diagram of uplifted nodes under the concentrated mass located on the fourth floor ( 65 nodes uplifted and the maximum uplift area ratio is $33.3 \%$ ).

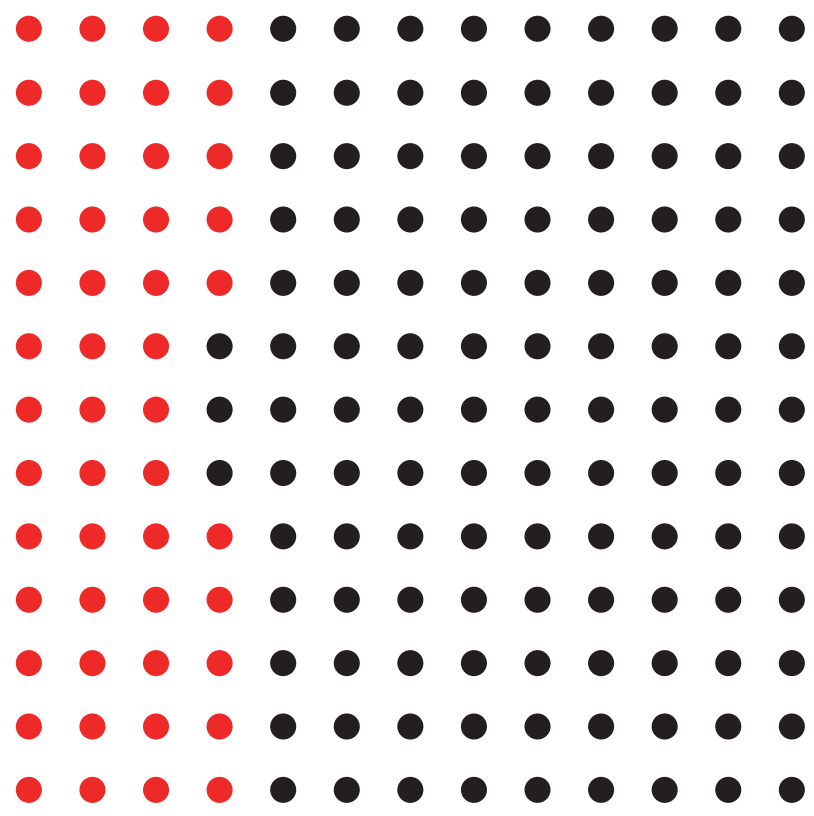

FIGURE 36: Schematic diagram of uplifted nodes under the concentrated mass located on the first floor (49 nodes uplifted and the maximum uplift area ratio is $22.2 \%$ ).

of structure. Some key factors, such as seismic waves, velocity of shear wave in soil, and structural characters, are analyzed and discussed. The following conclusions can be drawn from the above analysis and comparison:

(1) The vertical direction of input seismic wave has little influence on the seismic response of structure at horizontal direction, while it significantly affects the seismic response of structure in vertical direction, and the maximum uplifted 
area ratio of structure. This result is consistent with the earlier research results by Joe (1993) and Kennedy et al. (1976) and in turn verified the rational of the proposed method in current study.

(2) The seismic response of structure tends to be larger with the increase of the amplitude of input seismic wave.

(3) The type of seismic wave has a notable effect on structural responses. Regarding the structure and selected seismic waves in current paper, the seismic response of structure for the long-distance Songpan wave turns out to be tenser due to the fact that the dominant frequency of the seismic wave is very close to the natural frequency of structure.

(4) The velocity of shear wave in soil has certain influence on seismic response of structure. It is found that the stiffer the soil is, the easier the occurrence of the base mat uplift is.

(5) The ratio of structural height to width $(H / B)$ has a complicated influence on the base mat uplift. It is found that higher structure with smaller width theoretically tends to make base mat uplift easier. However, in higher structure, the structural stiffness tends to decrease and total weight of structure tends to increase, which in turn prevents the base mat uplift. Therefore, the net effect will be determined by the factor which is dominant.

(6) The influence of auxiliary equipment on the seismic response of structure mainly depends on its weight and location.

As has been stated previously, simulation of rocking system in seismic analysis obviously involves nonlinearity of soils and the interface between structure and soil in terms of both stress-strain relationship and geometry aspects. For the sake of simplicity, only geometry nonlinearity has been considered in this paper. In case of strong earthquake where nonlinear stress-strain relationship is prominent in material response, such property will absorb certain amount of energy and thus benefit the structure in terms of earthquakeproof capability. Further analysis should be carried out in light of more accurate simulation on nonlinearity in future researches.

\section{Conflicts of Interest}

The authors declare that they have no conflicts of interest.

\section{Acknowledgments}

The authors are thankful for the support from the Natural Science Foundation of China (nos. 51208406, 51678465) and Scientific Research Foundation for Chinese Ministry of Education for Returned Overseas Researchers.

\section{References}

[1] M. Apostolou, G. Gazetas, and E. Garini, "Seismic response of slender rigid structures with foundation uplifting," Soil Dynamics and Earthquake Engineering, vol. 27, no. 7, pp. 642654, 2007.

[2] G. W. Housner, "The behavior of inverted pendulum structures during earthquake," Bull. Seism. Soc, vol. 53, pp. 403-417, 1963.
[3] C. S. Yim, A. K. Chopra, and J. Penzien, "Rocking response of rigid blocks to earthquakes," Earthquake Engineering \& Structural Dynamics, vol. 8, no. 6, pp. 565-587, 1980.

[4] A. S. Koh, P. D. Spanos, and J. M. Roesset, "Harmonic rocking of rigid block on flexible foundation," Journal of Engineering Mechanics, vol. 112, no. 11, pp. 1165-1180, 1986.

[5] C. W. Harden and T. C. Hutchinson, "Beam-on-nonlinearwinkler-foundation modeling of shallow, rocking-dominated footinǵs," Earthquake Spectra, vol. 25, no. 2, pp. 277-300, 2009.

[6] M. F. Vassiliou, K. R. Mackie, and B. Stojadinović, "Dynamic response analysis of solitary flexible rocking bodies: Modeling and behavior under pulse-like ground excitation," Earthquake Engineering and Structural Dynamics, vol. 43, no. 10, pp. 14631481, 2014.

[7] S. Acikgoz and M. J. DeJong, "The rocking response of large flexible structures to earthquakes," Bulletin of Earthquake Engineering, vol. 12, no. 2, pp. 875-908, 2014.

[8] F. Gelagoti, R. Kourkoulis, I. Anastasopoulos, and G. Gazetas, "Rocking isolation of low-rise frame structures founded on isolated footings," Earthquake Engineering and Structural Dynamics, vol. 41, no. 7, pp. 1177-1197, 2012.

[9] I. Anastasopoulos, G. Gazetas, M. Loli, M. Apostolou, and N. Gerolymos, "Soil failure can be used for seismic protection of structures," Bulletin of Earthquake Engineering, vol. 8, no. 2, pp. 309-326, 2010.

[10] K. Sotomura and H. Kase, "Nonlinear response analysis on reactor building subject to horizontal and vertical ground motion simultaneously," in Inproceedings of the 7th International Conference on Structural Mechanics in Reactor Technology (SMiRT7), pp. 341-348, Chicago, 1983.

[11] G. Gazetas, I. Anastasopoulos, and E. Garini, "Geotechnical design with apparent seismic safety factors well-bellow 1," Soil Dynamics and Earthquake Engineering, vol. 57, pp. 37-45, 2014.

[12] G. Gazetas, "4th Ishihara lecture: Soil-foundation-structure systems beyond conventional seismic failure thresholds," Soil Dyn. Earthq, vol. 68, pp. 23-39, 2015.

[13] R. P. Kennedy, S. A. Short, D. A. Wesley, and T. H. Lee, "Effect on non-linear soil-structure interaction due to base slab uplift on the seismic response of a high-temperature gas-cooled reactor (HTGR)," Nuclear Engineering and Design, vol. 38, no. 2, pp. 323-355, 1976.

[14] N. Naohiro, A. Shodo, S. Takuya et al., "Study of ultimate seismic response and fragility evaluation of nuclear power building using nonlinear three-dimensional finite element model," Nucl. Eng. Des, vol. 240, pp. 3551-3560, 2010.

[15] C. Bolisetti and A. S. Whittaker, "Seismic structure-soilstructure interaction in nuclear power plant structures," in Proceedings of the 21th International Conference on Structural Mechanics in Reactor Technology (SMiRT21, p. 11, New Delhi, India, 2011.

[16] N. Yabushita, N. Nakamura, T. Suzuki et al., "Analyses of reactor by $3 \mathrm{D}$ nonlinear FEM models considering basement uplift for simultaneous horizontal and vertical ground motions," in Inproceedings of the 19th international conference on Structural Mechanics in Reactor Technology (SMiRT19), pp. 1-8, Toronto, 2007.

[17] N. Naohiro, I. Susumu, Y. Naoto, S. Takuya et al., "Analyses of reactor building by 3D nonlinear FEM models considering base mat uplift for simultaneous horizontal and vertical ground motions," Nucl. Eng. Des, vol. 238, pp. 166-180, 2008.

[18] I. Anastasopoulos, F. Gelagoti, A. Spyridaki, J. Sideri, and G. Gazetas, "Seismic rocking isolation of an asymmetric frame on 
spread footings," Journal of Geotechnical and Geoenvironmental Engineering, vol. 140, no. 1, pp. 133-151, 2014.

[19] I. Anastasopoulos, V. Drosos, and N. Antonaki, “Three-storey building retrofit: Rocking isolation versus conventional design," Earthquake Engineering and Structural Dynamics, vol. 44, no. 8, pp. 1235-1254, 2015.

[20] A. K. Chopra and S. C. Yim, "Simplified Earthquake Analysis of Structures with Foundation Uplift," Journal of Structural Engineering, vol. 111, no. 4, pp. 906-930, 1985.

[21] H. Tanaka, I. Maeda, K. Moriyama, and S. Watanabe, "Study on Horizontal Vertical Interactive SR Model for Base mat Uplift (Part 1 Formulation on Non-linear Characteristics of Soil Spring)," in Inproceedings of the 13th International Conference on Structural Mechanics in Reactor Technology (SMiRT13), pp. K081-K08-6, 1995.

[22] H. Masaeli, F. Khoshnoudian, and M. Hadikhan Tehrani, "Rocking isolation of nonductile moderately tall buildings subjected to bidirectional near-fault ground motions," Engineering Structures, vol. 80, pp. 298-315, 2014.

[23] A. S. Veletsos and B. Verbic, "Vibration of viscoelastic foundations," Earthquake Engineering \& Structural Dynamics, vol. 2, no. 1, pp. 87-102, 1973 .

[24] American Society of Civil Engineers Standard, "Seismic analysis of safety - related nuclear structures and commentary," ASCE, pp. 4-98, 1998.

[25] I. Rotaru, V. Serban, N. Krutzik, D. Papandreou, and W. Schütz, "Reanalysis and evaluation of the seismic capacity of the CANDU 700 MW NPP CERNAVODA," Nuclear Engineering and Design, vol. 212, no. 1-3, pp. 381-393, 2002.

[26] "Design of Nuclear Power Plants against seismic events part 4," in Proceedings of the Requirements for procedures for verifying the safety of mechanical and electrical components against earthquakes (KTA 2201. 4 (6/90)), vol. 4, 1990.

[27] Code for seismic design of buildings, in Chinese. 


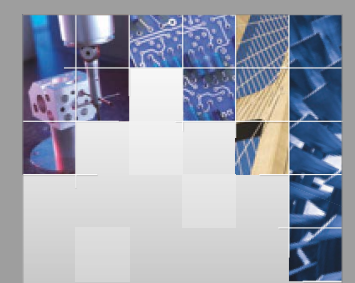

\section{Enfincering}
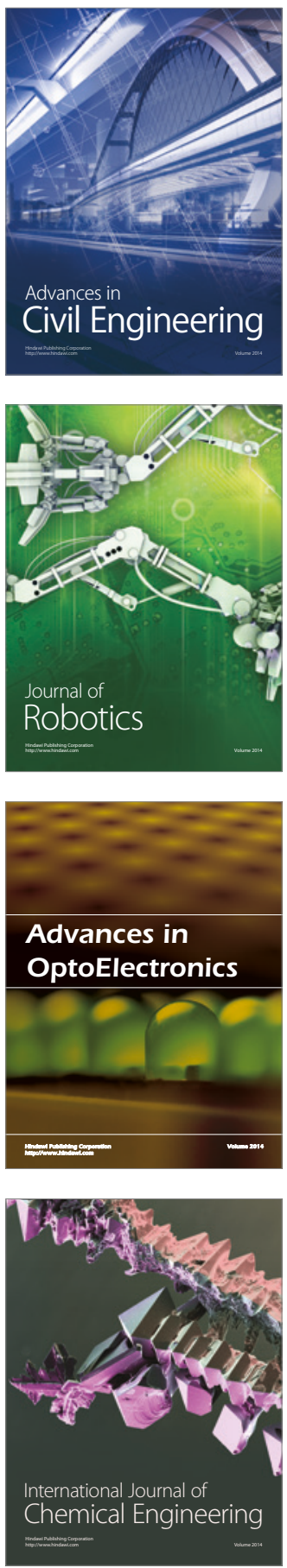

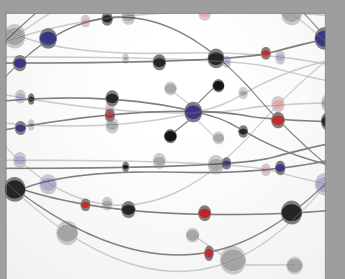

The Scientific World Journal

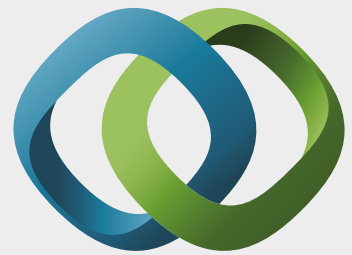

\section{Hindawi}

Submit your manuscripts at

https://www.hindawi.com
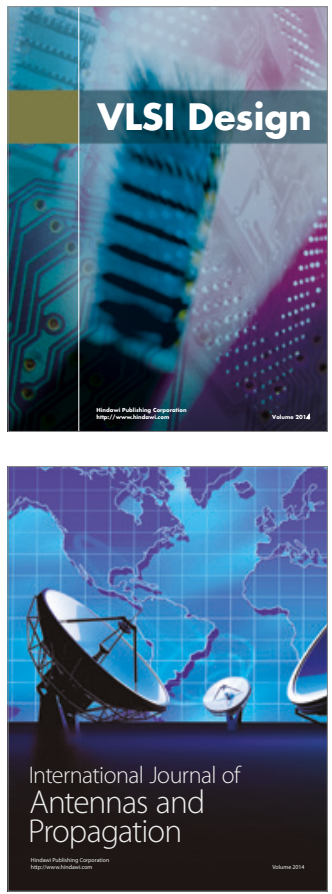

\section{Rotating}

Machinery
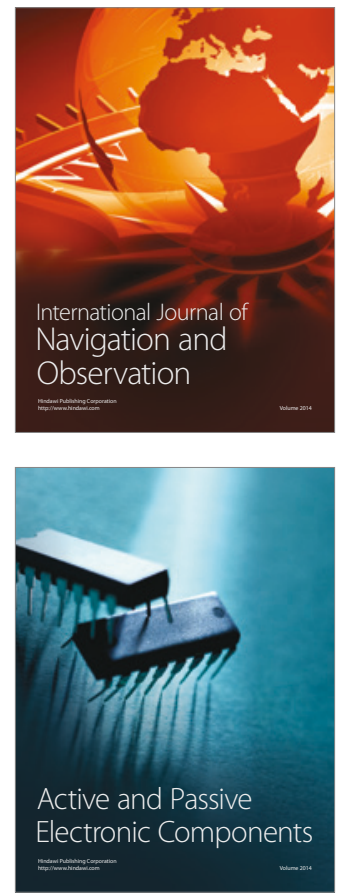
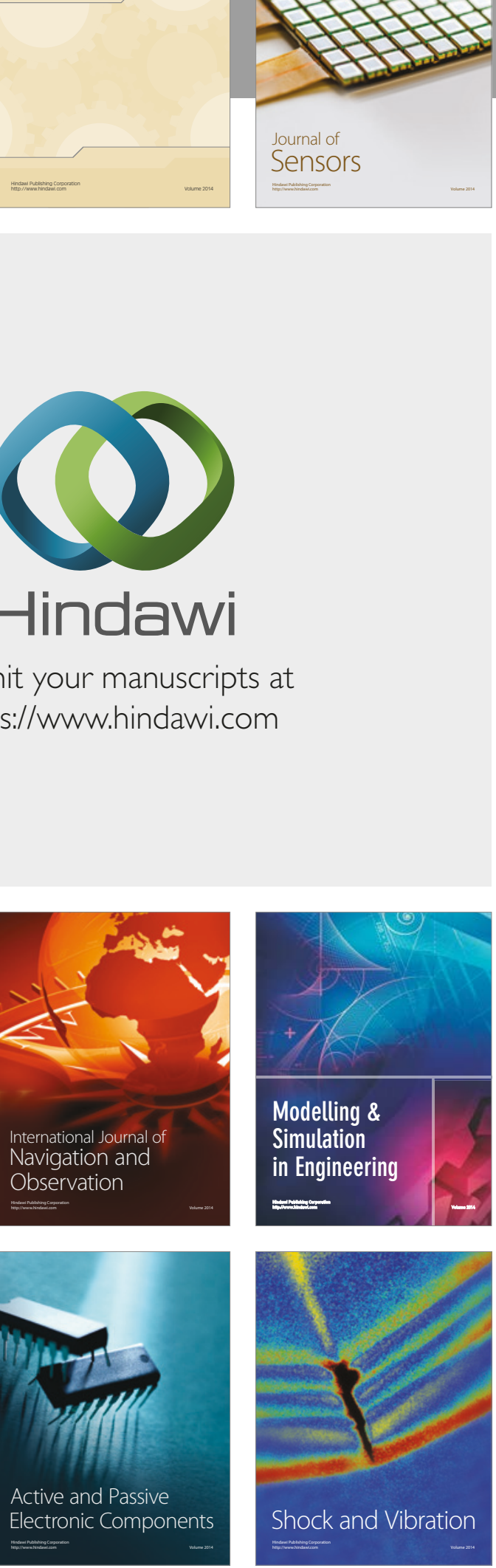
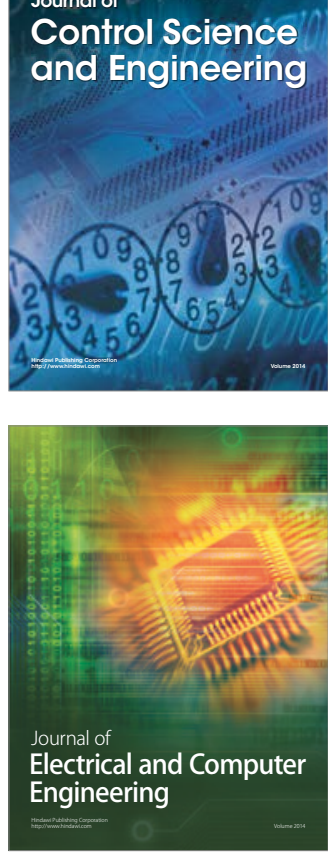

Distributed

Journal of

Control Science

and Engineering
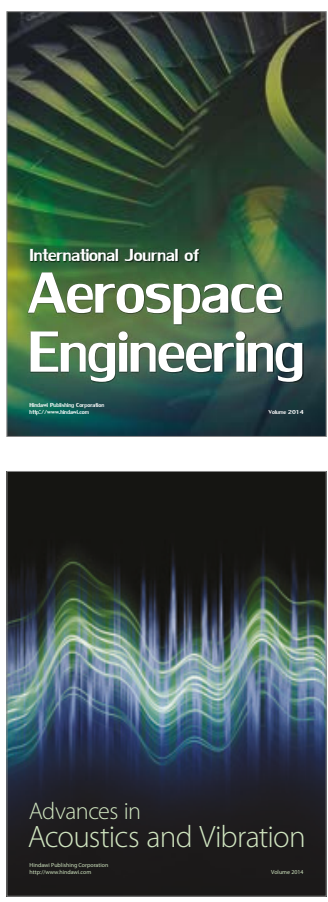

Sensor Networks 